\title{
The Potential Role of Sleep in Promoting a Healthy Body Composition: Underlying Mechanisms Determining Muscle, Fat, and Bone Mass and Their Association with Sleep
}

\author{
Fabia M. Stich ${ }^{a}$ Stephanie Huwiler ${ }^{a}$ Gommaar D'Hulst ${ }^{b}$ \\ Caroline Lustenberger ${ }^{a, c, d}$ \\ a Neural Control of Movement Lab, Department of Health Sciences and Technology, ETH Zurich, \\ Zurich, Switzerland; 'baboratory of Exercise and Health, Department of Health Sciences and \\ Technology, ETH Zurich, Zurich, Switzerland; ' Neuroscience Center Zurich, ETH Zurich and \\ University of Zurich, Zurich, Switzerland; ${ }^{\text {d}}$ Sleep \& Health Zurich, University Center of Competence, \\ University of Zurich, Zurich, Switzerland
}

\section{Keywords}

Body composition · Sleep architecture - Slow wave sleep · Tissue metabolism · Growth hormone

\begin{abstract}
Sleep plays an essential role in human life. While sleep is a state elicited by the brain, its vital role reaches beyond maintaining brain health. Unhealthy sleeping habits have been associated with increased risk for inflammation, obesity, or diabetes. Evidence is emerging that sleep guides processes playing an important role in promoting the regulation of endocrine function involved in tissue regeneration and tissue remodelling. Thereby, sleep presumably is a critical factor contributing to the balance of core body tissues: bone, fat, and muscle mass. Given the increasing prevalence of various chronic diseases and comorbidities due to unhealthy lifestyle choices, sleep could be a key target to promote a healthy body composition up until old age. Here, we review the potential role of sleep and its underlying brain oscillations in body core tissues turnover. Specifically, we discuss potential underlying mechanisms linking sleep to body
\end{abstract}

karger@karger.com www.karger.com/nen

Karger"

BOPEN ACCESS
(C) 2021 The Author(s)

Published by S. Karger AG, Basel

This is an Open Access article licensed under the Creative Commons Attribution-NonCommercial-4.0 International License (CC BY-NC) (http://www.karger.com/Services/OpenAccessLicense), applicable to the online version of the article only. Usage and distribution for commercial purposes requires written permission. composition, both during rest and under challenging conditions. Among other described pathways, we highlight the possible role of the growth hormone that was found to be involved in the homeostasis of all core body tissues and has been strongly linked to brain activity dominating deep sleep, the so-called slow waves. Finally, we formulate important questions to be addressed in future research on the effect of sleep on body composition and specifically emphasize the importance of intervention studies to move from correlative to causal evidence.

(c) 2021 The Author(s)

Published by S. Karger AG, Basel

\section{Introduction}

Spending around one-third of a lifetime sleeping, it is undeniable that sleep is essential to human life. While research revealing structural characteristics of sleep as for instance the distribution of sleep stages or underlying brain oscillations has been progressing with high speed, the functions of sleep remain poorly understood. Several studies have identified a potential role of sleep for brain 


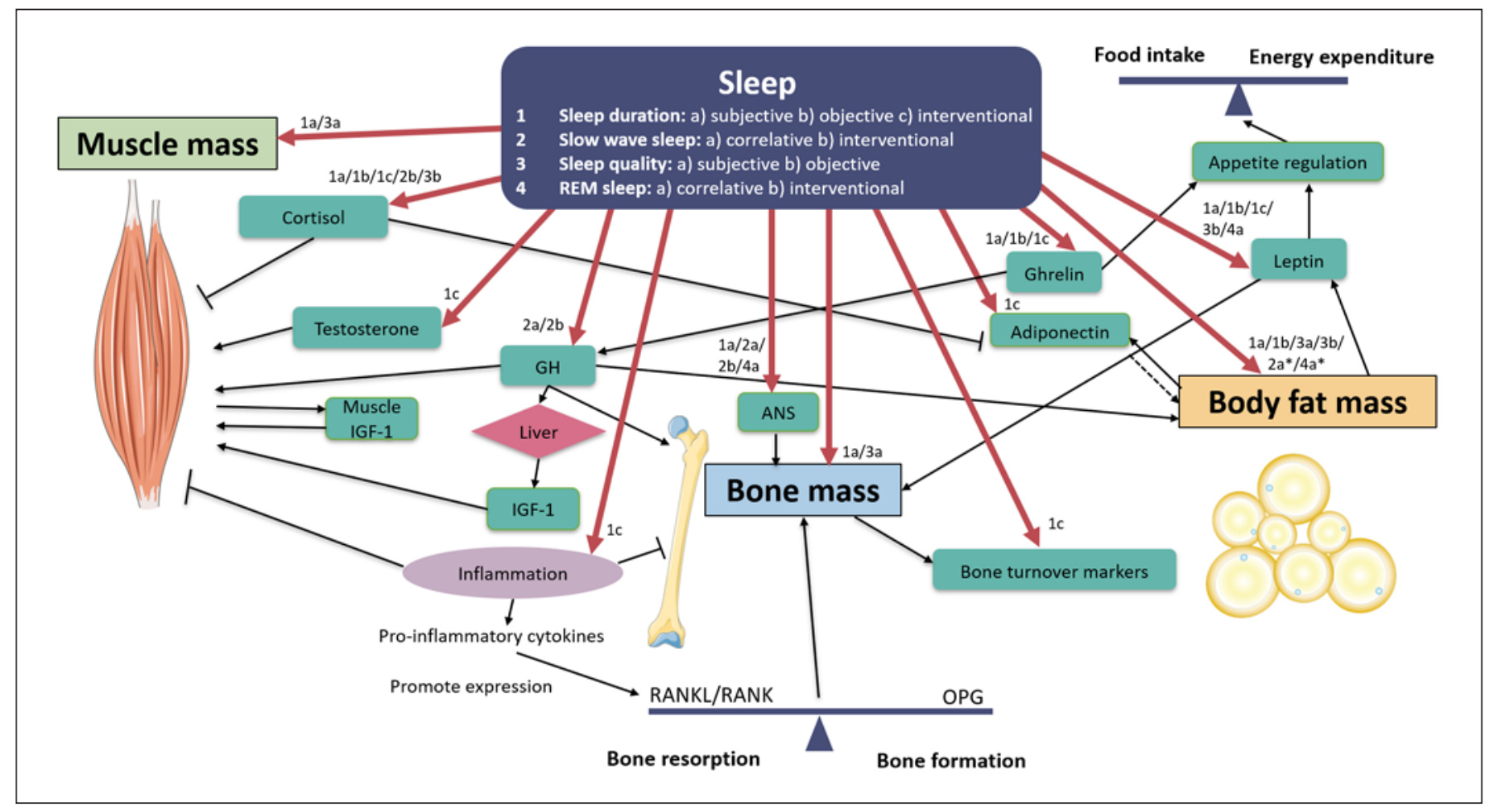

Fig. 1. Summary of potential pathways involved in the regulating body composition parameters and their relation to different sleep variables. Despite the directionality of the arrows, the direction of the relationship is not in all cases conclusively clarified. The numbers represent the sleep characteristic: $1=$ sleep duration, $2=$ slow wave sleep, 3 = sleep quality, and $4=$ REM sleep. The letters a, b, and $c$ indicate whether sleep was reported subjectively or objectively or whether the association was shown in an experimental study design (e.g., sleep intervention). Latter may already point to a causal relationship. Multiple numbers indicate a certain pathway or a molecule to be related to $>1$ sleep variable. Muscle mass (left),

health, such as cleaning away toxic by-products $[1,2]$, synaptic plasticity [3-6], and memory consolidation [1, 7-13]. In addition, an increasing number of studies point towards the fact that the restorative functions of sleep are not restricted to the brain only, but are also important for peripheral body functions, such as immune [14], cardiovascular [15], and metabolic functions [16]. By this time, it is generally accepted that sleep is an integral factor for people's health. Yet the underlying mechanisms and the specific involvement of sleep in peripheral body processes are still not fully understood.

The proportion of fat-free mass and fat mass in the body, often referred to as "body composition," is a key aspect determining overall health [17-19]. Evidently, nutrition and physical activity are essential factors determining body composition and have been studied thoroughly for bone mass (middle), and body fat mass (right) are all regulated by various mechanisms (black arrows pointing to the respective mass). *An association on body fat mass was not shown directly, but on body mass index instead. REM, rapid eye movement; GH, growth hormone; IGF-1, insulin growth factor 1; ANS, autonomic nervous system; RANK, receptor activator of NF- $\kappa B$; RANKL, receptor activator of NF- $\kappa \mathrm{B}$ ligand; OPG, osteoprotegerin. Used creative commons: adipocytes: by Database Center for Life Science (DBCLS) - License: CC BY; bone: by Servier Medical Art - License: CC BY; muscle: by Servier Medical Art - License: CC BY.

the last decades. Sleep, on the contrary, has gained much less attention as a central regulator of body composition, despite its pivotal role in regulating mass turnover [2022]. Therefore, this review aims to summarize current evidence on how sleep affects processes that build and remodel body composition under physiological conditions and upon system challenges, for example, through exercise or injury. Identifying and understanding the involvement of specific aspects of sleep in processes that determine body composition is key to identifying targets for prevention or treatment of pathological states of body composition. The present work starts by summarizing components of body composition and an introduction to sleep and sleep architecture. Thereafter, we will review existing literature on the association between sleep and aspects of body composition (muscle mass, fat, and bone 
density) with a focus on a physiological mass turnover as well as on studies investigating the role of sleep in the respective processes, which are summarized in Figure 1. Considering situations of intended change in body composition, a short paragraph will be devoted to the importance of sleep related to exercise, weight loss, and fracture healing. Finally, current limitations and items for a research agenda will be discussed. Taken together, this work aims to identify potential pathways that are regulated through sleep quality and quantity and may play a central role for body composition. However, the mechanisms discussed in this review are likely not complete and we assume that some pathways and processes linking sleep and body composition are not even known yet.

\section{Body Composition}

\section{Body Composition and Health}

Body composition has repeatedly been shown to be central to health and disease, although its importance often only becomes apparent in pathological states. Body fat, for example, is a complex tissue with critical metabolic and endocrine functions by for instance releasing hormones regulating energy expenditure [23]. However, when present in excessive amount as in obesity, its effect on health is no longer beneficial. In fact, cardiovascular diseases [24], hepatic steatosis [24], insulin resistance [24], neurological disorders [25], and cancer [24] can all occur comorbid to obesity and drastically reduce life expectancy. Furthermore, low muscle mass, resulting from an imbalance between muscle protein synthesis and muscle protein breakdown, results in muscle atrophy [26], which at a later stage can result in detrimental outcomes such as disability, decreased quality of life, and increased mortality [27, 28]. Finally, decreased bone mass known as osteopenia can further progress to osteoporosis, a state of low bone mineral density, and an increased rate of bone resorption $[19,29]$. Osteoporosis is an important risk factor for bone fractures and increased risk of falling [30, 31]. Obesity, muscle atrophy, and osteoporosis are all representing unique unhealthy changes in body composition parameters and put an immense burden on the health of individuals as well as on health care costs [32]. Therefore, finding a means to keep body composition in a healthy range or to improve pathological alterations of body composition is of great interest. Besides the well-known importance of healthy nutrition and physical activity for body composition $[33,34]$, sleep with its restorative functions is likely to be critically involved.

Sleep and Body Composition

\section{Body Composition Assessment Methods}

To diagnose healthy and pathological states of body composition, dual energy X-ray absorptiometry (DXA) is currently the reference standard, providing precise assessments of core body tissues [35]. Less expensive but also less accurate alternatives to DXA are bioelectrical impedance analysis (BIA), waist circumference, waist-tohip ratio, or the body mass index (BMI), which are commonly used assess body composition parameters [36]. Although BMI is the most widely used measure in population studies, it has clearly some limitations. BMI does, for example, not consider where the fat is located, which in some situation is the key factor influencing disease risk. For instance, as the visceral adipose tissue is known to be more closely associated with cardiovascular risk than the subcutaneous adipose tissue, assessing that waist circumference or waist-to-hip ratio could be beneficial over $\mathrm{BMI}$. However, as on population level the BMI is a valid construct correlating well with measures of body composition and comorbidities from obesity, BMI is still the most widely used obesity measurement in the general population $[37,38]$.

\section{Sleep}

\section{Sleep Regulation}

Sleep regulation is governed by 2 interacting processes, the circadian and the homeostatic processes, a bimodal regulation that is commonly explained by the " 2 process model" $[39,40]$. The homeostatic process, called process $S$, refers to the continuous build-up of sleep pressure during wake time. For this pressure to subside, sleep is required no matter at what time of the day/night. On the other hand, process $\mathrm{C}$, a process controlled by the circadian pacemaker, is independent of sleep and rises and falls periodically. The circadian pacemaker orchestrates many of the body's internal biological processes, including core body temperature, feeding patterns, and hormone production in a highly rhythmic pattern [41]. Although processes $\mathrm{S}$ and $\mathrm{C}$ are known to act mostly independently of each other, they both influence sleep and sleep patterns in a highly complex and additive manner [42]. While both sleep and the circadian rhythm are involved in metabolic functions, here we solely focus on effects caused by sleep itself. Controlled approaches aiming to identify the contributions of sleep are sleep restriction or sleep modulation studies (e.g., modulation of specific aspects of sleep architecture) [43-45]. These studies compare a molecule or a hormone of interest in a sleep-de- 


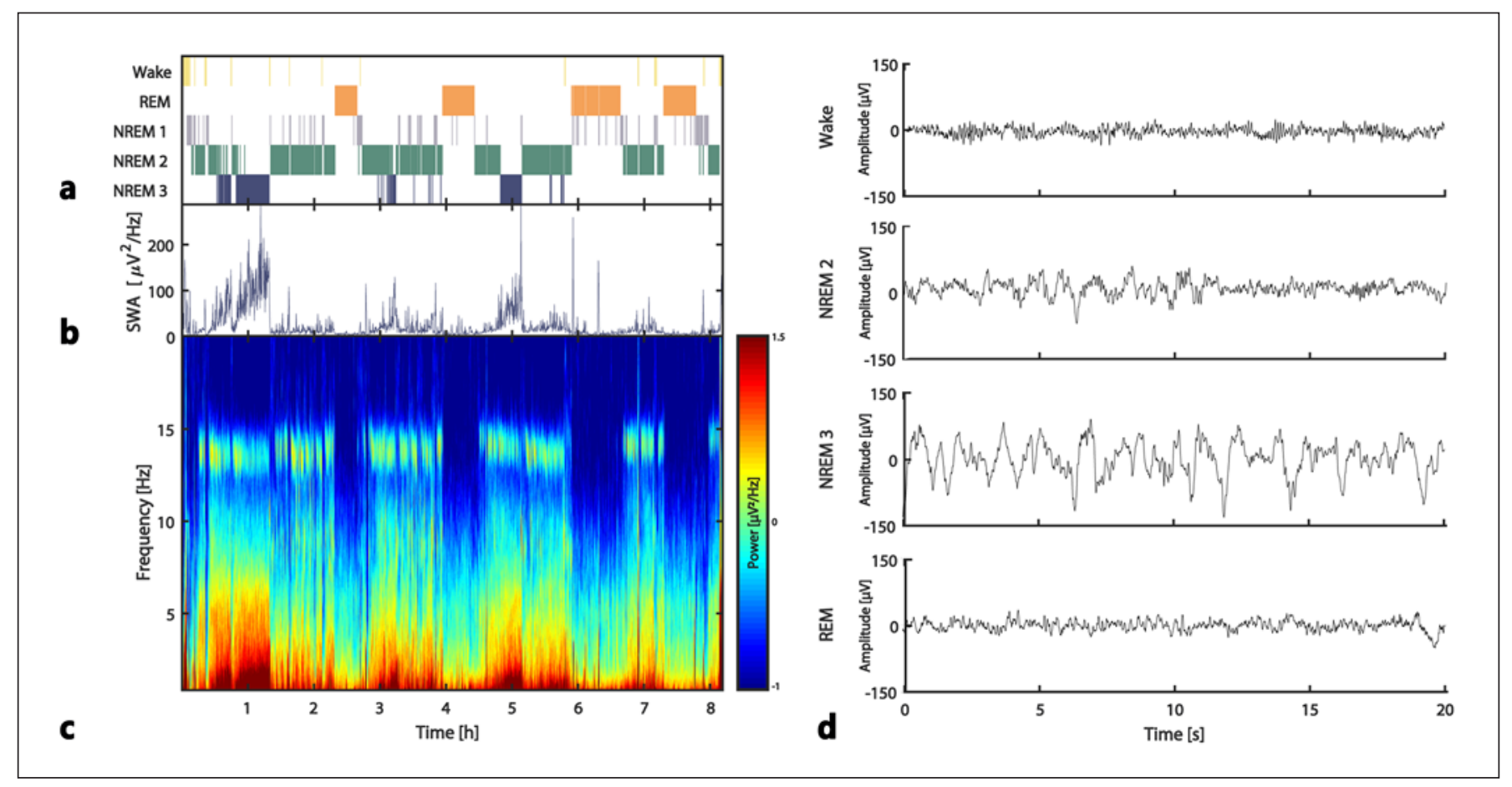

Fig. 2. a Hypnogram showing distribution of sleep stages (wake, REM, and NREM sleep stages 1, 2, and 3) across an exemplary subject. b SWA $(0.5-4.5 \mathrm{~Hz})$ of electrode Pz of full night sleep. c Spectrogram of electrode Pz across full night. d Schematic illustration of the EEG activity of a frontal electrode to mastoid abbreviation (F3A2) for wake, NREM2, NREM 3 (SWS), and REM sleep. High-amplitude slow waves dominate during NREM 3. SWA, slow wave activity; REM, rapid eye movement; NREM, non-rapid eye movement.

prived/modulated condition to a sleep-sufficient/unmodulated condition [16, 46, 47]. However, in some cases, a clear distinction between sleep and circadian contributions is not possible and those cases will be addressed in the respective References of the review.

\section{Sleep Architecture}

A major breakthrough in the field of sleep science was the development of the electroencephalogram (EEG), which enabled researchers to reliably measure activity in the brain mediated by changes in the electrical activity of large populations of neurons [48]. The EEG allows to detect changes in brain activity between wake and sleep, and also between sleep stages [49], as illustrated in Figure 2d. Those synchronized brain activity patterns at specific frequencies (seen as EEG rhythms) can be categorized into oscillation bands. Human nocturnal sleep periods are hallmarked by a cycling pattern between non-rapid eye movement (NREM) and rapid eye movement (REM) sleep, with an approximate duration of 90-120 min per sleep cycle $[49,50]$. NREM sleep is characterized by sleep spindles (transient thalamocortical oscillations between
11 and $16 \mathrm{~Hz}$ ) and slow waves [51]. These slow waves are high amplitude, low-frequency waves (e.g., $<4 \mathrm{~Hz}$ ), and an increase in number and size as sleep deepens. The transition from NREM stage 2 (N2) into NREM stage 3 (N3), the deepest stage of sleep, is characterized by the presence of slow waves during $>20 \%$ of the time [49]. This stage is therefore also termed slow wave sleep (SWS). The distinction between REM sleep and wake brain activity is difficult because of the absence of dominant oscillations. However, REM sleep is characterized by decreased muscle tone, reflecting muscle atonia, and REMs, that can both be identified using electromyogram and electrooculogram, respectively, in addition to the EEG $[49,52]$. As the night advances and the morning approaches, the length of REM sleep increases, while the NREM stages become shorter, representing a significant change of the proportion of REM/NREM sleep within a sleep cycle across the night [53]. An exemplary sleep architecture of a night is illustrated in Figure 2a. Besides some natural changes in sleep architecture across consecutive nights, particularly healthy ageing is associated to affect the duration and proportion of sleep stages. Older age is associ- 
ated with a markedly reduction of amount and extent of SWS $[54,55]$. Thus, the physiological decline in total sleep duration with increasing age makes sleep in the elderly a suitable model to study the relationship between SWS and body composition. In addition to quantitative changes in SWS, sleep gets more fragmented and shorter with increasing age [56], whereas the percentage of REM sleep remains fairly stable [57].

\section{Sleep Assessment Methods}

The gold standard for the reliable estimation for sleep and wake times, but also the assessment of sleep architecture and the detection of sleep oscillations is polysomnography (PSG) [58]. This method involves several measures of sleep, including brain activity measured by EEG, muscle activity (electromyogram), and eye movements (electrooculogram). These recordings can be accompanied by heart activity and respiratory function, for example, for sleep disorder screening such as sleep apnoea [58]. Since PSG assessments are costly, complex, and require expensive equipment, studies often approximate sleep and wake duration as well as sleep quality (e.g., sleep continuity) with actigraphy [59]. This method involves a wearable device usually worn on the wrist or ankle that records body acceleration. Therefrom, together with mathematical algorithms, wake times, sleep times, and rough approximations of sleep stage parameters can be calculated [60]. Besides objective sleep assessments, perceived sleep quality and quantity can be assessed by questionnaires such as the Pittsburgh Sleep Quality Index (PSQI), which includes different items and finally provides a global score with higher values indicating worse sleep [61]. Collectively, questionnaires and actigraphy are often assessed in home settings, whereas PSG is usually carried out in a sleep laboratory [59].

\section{Sleep and Muscle Mass}

Skeletal muscle mass is, apart from its key role in locomotion, also a metabolic organ that is essentially involved in whole-body homeostasis [62-64]. Skeletal muscles in a healthy adult comprise about $38 \%$ of total body mass in men and approximately $30 \%$ in women [65]. A significant loss in muscle mass and strength with increasing age is defined as sarcopenia, entailing a loss of functionality, which may result in disability and an increased risk for chronic diseases including insulin resistance, fatigue, and mortality [66-69]. Therefore, finding means to preserve muscle mass with old age may improve musculoskeletal and overall health. Besides optimized nutritional and physical activity regimen, prioritizing healthy sleep could aid in preserving muscle mass.

The influence of sleep on muscle mass has been the focus of several studies reporting an increased prevalence for lower muscle mass and sarcopenia in short sleepers as well as those who reported habitual poor sleep quality [70-77]. Besides muscle mass, poor subjective sleep quality and sleep efficiency were also associated with decreased grip strength, underlining the relevance of sleep for functional aspects of muscle mass [72]. Sleep deprivation is proposed to influence the balance between synthesis and breakdown of muscle proteins by increased proteolysis [78], which ultimately leads to a loss of muscle mass. This view is supported by the observation of higher urinary protein secretion after $72 \mathrm{~h}$ of sleep deprivation, which is characteristic for enhanced proteolytic processing [79]. A study directly highlighting the negative effects of short sleep on body composition showed that while on a 14-day calorie-restricted diet, the change of fat and muscle mass significantly varied with the allowed sleep time, that is, $8.5 \mathrm{~h}$ or $5.5 \mathrm{~h}$ (sleep restriction). More specifically, weight loss was comparable in both groups $(\sim 3$ $\mathrm{kg})$. However, participants in the short sleep condition showed a 55\% lower decrease in fat mass and a $60 \%$ higher decrease in muscle mass than the volunteers that had the $8.5 \mathrm{~h}$ sleep opportunity per night. The longitudinal experimental design implies that during sleep, key processes involved in muscle metabolism occur, which are required to preserve muscle mass during a calorie-restricted diet [80]. Short sleep may therefore undermine the efficacy of the diet-induced loss of body fat.

Apart from experimental studies investigating the effect of partial or total sleep restriction on muscle mass, observational studies of sarcopenic patients provide useful information on the link between muscle mass metabolisms and sleep. As proposed by Piovezan et al. [81], the underlying mechanisms for age-related sarcopenia may be associated with changes in sleep patterns. Their hypothesis builds on the evidence that older adults show decreased sleep time and efficiency along with a significant decrease in the amount and intensity of SWS. This decrease is paralleled by a dysregulation of the somatotropic, gonadal, and corticotropic activity as well as glucose metabolism, all of which are critically involved in muscle metabolism $[81,82]$.

\section{Underlying Mechanisms}

To maintain a constant mass of muscle tissue, a balance between muscle anabolism mediated by protein synthesis and muscle catabolism is required. Any imbalance, 


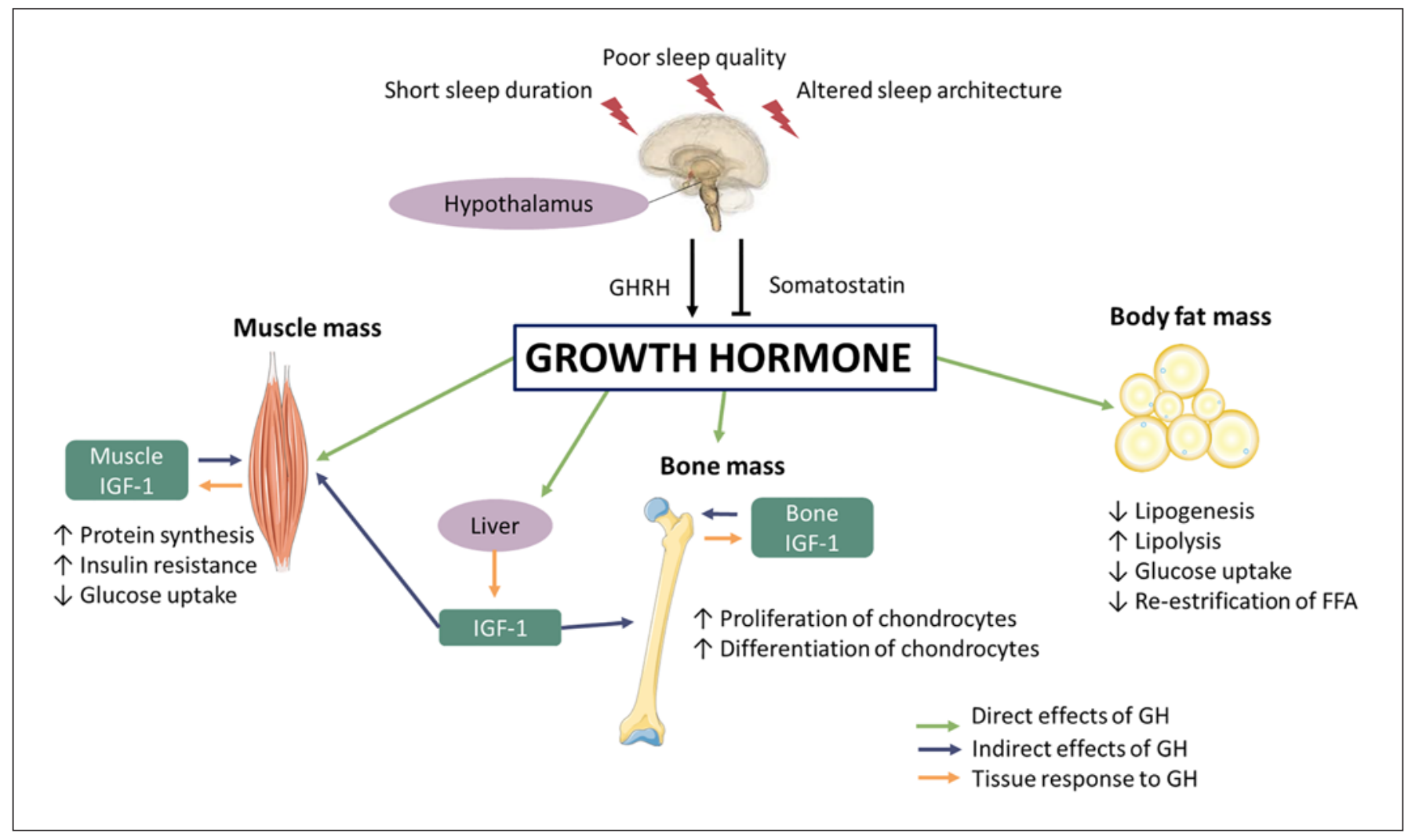

Fig. 3. GH is critically involved in the regulation of muscle-, bone, and body fat mass and is affected by different types of sleep disturbances. $\mathrm{GH}$ is known to act by 2 different mechanisms, directly by binding to the its receptor on target tissues and ultimately leading to the induction of signalling cascades or via its indirect mode of action via IGF-1. IGF-1 is secreted mainly by liver but also by other tissues including bone and muscle in response to GH. While in bone and muscle tissue both modes of actions are important, the action of GH on body fat is suggested to be mediated by its direct effect only. Used creative commons: brain: by Nickbyrd - License: CC BY-SA; adipocytes: by Database Center for Life Science (DBCLS) - License: CC BY; bone: by Servier Medical Art - License: CC BY; muscle: by Servier Medical Art - License: CC BY. GH, growth hormone; IGF-1, insulin-like growth factor 1; GHRH, growth hormone-releasing hormone. especially over longer time periods, leads to muscle hypertrophy when protein synthesis dominates, or muscle atrophy when protein degradation is prevalent [83]. In the following paragraphs, we first identify pathways involved in the synthesis and breakdown of muscle proteins and second highlight whether and how these are modulated by sleep. A summarizing graphical overview of potential underlying mechanisms discussed below is presented in Figure 1.

\section{Insulin-Like Growth Factor 1/Growth Hormone}

Growth hormone $(\mathrm{GH})$ is a central player in the promotion of somatic growth and has a pivotal role in metabolism including the regulation of glucose, lipolysis, and protein synthesis [84]. GH can either act directly or indirectly via the $\mathrm{GH}$-induced insulin-like growth factor
1 (IGF-1) secretion, both mechanisms being shown to stimulate muscle protein synthesis [84]. Primary evidence for the muscle mass stimulating effect of $\mathrm{GH}$ comes from the observation that the treatment of GH-deficient subjects with GH could significantly increase skeletal muscle mass [84]. Similarly, the administration of supraphysiological levels of GH with and without additional exercising in healthy adults has also repeatedly been shown to increase lean body mass [85-87]. However, variations in physiological levels of $\mathrm{GH}$ do not modulate muscle growth in adults [88], whereas cumulative deficits over longer time periods, as observable in older adults [89], could negatively affect muscle metabolism. Thus, age-related changes in body composition are hypothesized to be related to or caused by decreased levels of GH, a concept known as "somatopause" [90] (see Fig. 3). 
When investigating the effect of sleep on the GH/IGF1 axis, GH rather than IGF-1 secretion is of central importance. The secretion pattern of GH has been shown to follow a 24-h pattern, with sleep being an important window of most pronounced GH release [84]. A high GH release can specifically be observed soon after sleep onset temporally associated with the first episode of SWS [91, 92]. SWS as well as GH levels show a significant gradual decline with increasing age [93]. Moreover, GH secretion was shown to be highly associated with the percentage of SWS even after controlling for age [93]. Therefore, SWS seems to play a key role in the regulation of GH secretion. These observations are in line with previous findings from a study in which van Cauter et al. [94] showed that stimulation of SWS by gamma-hydroxybutyrate (GHB) doubled the secretion of $\mathrm{GH}$ in the first $2 \mathrm{~h}$ after sleep onset. In contrast, Besedovsky et al. [95] reported no significant difference of GH secretion when they acoustically enhanced slow waves and speculated that the increase in slow wave activity (SWA) may have been not strong enough to affect $\mathrm{GH}$ secretion in a young population. Furthermore, the lack of an effect on GH secretion might be due to its secretion being controlled by other aspects of sleep [95]. More specifically, while sleep seems to be the primary regulator of $\mathrm{GH}$ release, a circadian contribution could likewise be at play [96]. For instance, observations from a study investigating GH concentration in permanent night- and daytime workers support the presence of a relevant circadian regulation. Even though both groups showed similar amounts of SWS, night-time workers had a lower $\mathrm{GH}$ secretion during their daytime sleep than daytime workers during their nightly rest. The total amount of GH secreted over $24 \mathrm{~h}$, however, did not differ between the groups, suggesting a potential compensatory mechanism [96]. So far, we have only focused on possible mechanisms on how sleep affects GH. However, there is evidence for a reciprocal relationship. From animal [97] and human studies [98, 99], it is known that the growth hormone-releasing hormone (GHRH), released by the hypothalamus, stimulates NREM sleep intensity and/or duration and SWS in particular $[98,100,101]$. In contrast, preliminary findings on the effect of GH on sleep indicate that GH itself mainly promotes REM sleep $[102,103]$. This implies that patients with GH deficiency (GHD) (e.g., Sheehan syndrome, GHD of pituitary origin), where low levels of GH lead to an impaired negative feedback mechanism on GHRH and subsequently to excessive GHRH [104], would have longer SWS and less REM sleep than healthy controls. In situations where the GHD originates in the hypothala- mus (e.g., Prader-Willi syndrome), a different phenotype is expected: due to a disrupted hypothalamic function, GHRH levels are low together with GH levels. Consequently, decreased SWS and REM sleep compared to ageand sex-matched controls are expected. However, while the expected alterations in sleep were repeatedly observed $[98,99,105,106]$, only few studies have been able to show a reversibility of the altered sleep characteristics through GH administration yet $[102,107,108]$.

In conclusion, apart from the role of sleep in regulation of GH levels, the effect of GH/GHRH on sleep characteristics also warrants attention because clinical and experimental data support the presence of a reciprocal interaction between $\mathrm{GH}$ and sleep physiology. Given the inconclusive results, experimental studies investigating the bidirectional relationships and underlying mechanisms are needed. Due to the fact that patients with GHD often have increased fat mass and reduced lean mass [109-111], they might represent an interesting model to additionally study how the altered hormone status influences body composition.

\section{Testosterone}

Testosterone is not only influencing male secondary sex characteristics but also has anabolic muscle effects [112]. Various mechanisms how testosterone may induce muscle hypertrophy have been suggested, including the commitment of pluripotent stem cells to differentiate into cells of the myogenic type [112]. Studies investigating how testosterone secretion patterns are affected by sleep have mostly been conducted in men only [113]. Nonetheless, testosterone was shown to play a central role in female muscle and bone anabolism too [113]. In elderly women, higher levels of circulating testosterone have directly been associated with increased lean body mass [114], thereby supporting evidence that the effect of testosterone is not restricted to men only. Because women can also increase muscle mass despite having extremely low concentrations of testosterone, this implies that supraphysiological rather than physiological doses of testosterone are responsible for the shift towards muscle anabolism $[115,116]$. The circadian component in the secretion of testosterone is responsible for to levels peaking in the early morning and its decrease during the day [117-119], while an ultradian rhythm leads to the burstlike secretion pattern of testosterone in 90 -min intervals [120]. Starting after sleep onset, testosterone levels gradually rise until they reach a plateau coinciding with REM sleep onset [121]. Although the rhythm of nocturnal testosterone secretion seems to be related to the cycling be- 
tween REM and NREM phases [122], Evans et al. [123] observed that REM sleep does not directly lead to a production of testosterone. Axelsson et al. [124] observed a rise in testosterone during daytime sleep, with decreasing levels upon awakening, implying that testosterone levels in healthy young men are mainly regulated by sleep and weakly by circadian influences. In addition, a 1-week sleep restriction in healthy men $(<6 \mathrm{~h}$ sleep/night) led to significantly lower testosterone levels than a rested condition ( $>8 \mathrm{~h}$ sleep) [125]. As ageing is associated with decreased testosterone levels in men and women, testosterone administration to re-establish physiological levels can be considered to prevent the age-related loss in muscle mass [116, 126-133]. The significant decrease of sleep duration as well as sleep efficiency and especially percentage of SWS with age may at least partially explain the reduced testosterone secretion in elderly.

\section{Cortisol}

Contrary to the anabolic hormone testosterone, cortisol shows catabolic effects for muscle hypertrophy [134]. Cortisol, commonly called "stress hormone," is secreted in response to many types of physiological and psychological stress [135], while to some extent required, supraphysiological levels of cortisol have been suggested to modulate muscle protein metabolism through increased catabolism [136] and decreased synthesis of muscle proteins [137]. Pathological hypercortisolism as observed in Cushing's syndrome [138] shows characteristic proximal muscle weakness among other symptoms associated with an unfavourable effect on body composition such as abdominal fatty tissue deposits or bone loss [138]. Biopsic investigations of muscular tissue from patients with Cushing's disease also revealed morphological changes in muscles, seen as damaged mitochondria in muscular tissue, malformations of muscle fibres, and wide interfibrillar spaces [139].

Since cortisol secretion is enhanced under stress [135], one might expect that NREM sleep, as a relaxing state of human body and brain, is associated with decreased cortisol levels. However, varying cortisol levels between sleep and wake [140] can be a result of either the circadian control of hormone release, the influence of sleep itself, or even a combination of both. Therefore, controlled experiments to elucidate the respective influence of these 2 processes are needed. Evidence for the regulation by a circadian mechanism suggests that the release of cortisol is under the control of the central and peripheral circadian clocks. In turn, this leads to a peak of cortisol levels at the start of the activity phase, which, for diurnal organisms such as humans, is in the mornings [141]. However, sleep itself also contributes to cortisol secretion and the regulation of plasma cortisol concentrations [142]. An inhibitory effect of sleep leading to a decreased secretion of cortisol was found independent of sleep timing within the circadian rhythm in a 4-day sleep restriction protocol including sleep phase shifts and total sleep deprivation [143]. Further evidence showed that cortisol levels were significantly higher after $36 \mathrm{~h}$ of sleep deprivation than control and recovery nights [144]. Taken together, short sleep and total sleep deprivation are associated with increased cortisol levels independent of the circadian phase [143-145]. Apart from sleep duration, several studies investigated whether an association between sleep quality and cortisol levels exists. Poorer sleep quality, subjectively assessed by PSQI and objectively by actigraphy, was associated with a smaller early-morning cortisol decline and a slower rate of cortisol decline later in the day [146]. Specifically, SWS was shown to suppress the release of cortisol [14], with a variation in the secretion pattern that is temporally associated with the power spectral density in the slow wave EEG band (SWA) [147]. SWA across an exemplary night is illustrated in Figure 2b. Furthermore, selective enhancement of slow waves through acoustic stimulation led to a significantly reduced cortisol concentration during the first hour of stimulation, with a significant reduction already after $5 \mathrm{~min}$ of stimulation [95]. These observations are comparable to previous results from studies in which SWA was enhanced by pharmacological agents [106, 148]. Grimaldi et al. [149] reported significantly reduced evening-to-morning increases in cortisol when SWA was increased using acoustic stimulation compared to sham stimulation. However, they did not find a change in total cortisol levels after sleep following acoustically enhanced SWA. It should be noted though that, contrary to other studies, blood samples for cortisol testing were only drawn in the evening prior to sleep and in the morning [149]. Thus, cortisol levels may already have had risen when the blood sample was drawn in the morning and thereby the lowest concentrations may have been missed.

\section{Inflammation}

While so far focusing on hormones and peptides, the presence of a chronic low-grade inflammatory environment is likely to be another mechanism, which relates muscle mass metabolism to sleep [150]. As reviewed by Beyer et al. [150], there is a consistent association of agerelated sarcopenia and chronic low-grade inflammation [150]. Both systemic $[151,152]$ and tissue-specific [153- 
156] inflammatory markers were negatively associated with muscle mass and inflammation-related pathways. Moreover, numerous total and partial sleep restriction studies exist, showing an increment in markers for acute inflammation such as interleukin-1 (IL-1), tumour necrosis factor alpha (TNF- $\alpha$ ), IL-6, and C-reactive protein (CRP) in response to sleep manipulation in humans [157]. Negative effects of inflammatory environments have mostly been examined in relation to cardiovascular disease. However, enhanced expression of these cytokines is also known to interfere with other physiological pathways such as impaired muscle anabolism or increased muscle protein breakdown [158]. TNF- $\alpha$ as one example of a pro-inflammatory cytokine that is sensitive to sleep restriction is known to play a critical role in cachexia, a pathological condition causing ongoing muscle loss [159]. The underlying mechanism involves NF- $\kappa \mathrm{B}$ transcription factors, which are expressed in skeletal muscle, where they act as effect mediators of pro-inflammatory cytokines. In several sleep restriction studies as for instance by Irwin et al. [160], peripheral NF-kB levels were compared between baseline sleep, partial sleep deprivation, and recovery sleep. Results revealed a significantly increased NF- $\kappa$ B concentration in the morning after partial sleep deprivation compared to the other conditions [160]. Similarly, TNF- $\alpha$ receptor 1 and IL- 6 were elevated following experimentally induced total sleep restriction [161]. Moreover, elevated CRP levels, a strong predictor for cardiovascular morbidity, were observed following partial and total sleep restriction compared to a sufficient sleep condition [162]. Taken together, several studies found an increment of pro-inflammatory cytokines during nights of short sleep. However, whether these changes in inflammatory levels due to impaired sleep translate into impaired muscle protein synthesis, both in the short and long-term, remains to be investigated.

\section{Limitations and Implications}

Concentrations and secretion patterns of various key players in muscle metabolism have been shown to be related to or affected by sleep. In addition, impaired sleep has been linked to reduced muscle mass and function [72, $163,164]$, implying that sleep potentially affects muscle homeostasis. Yet, studies that directly link sleep and muscle mass as well as additionally provide a causal link of any of these pathways are still lacking. A positive influence of sleep on muscle anabolism is supported by studies that followed a sleep restriction protocol $[80,165]$. However, they solely assessed the adverse effect of an insufficient amount of sleep and never examined whether specific sleep cycles, sleep-specific oscillations, or certain sleep stages such as REM or NREM contribute to the observed effects. While research on the mechanism how GH and cortisol secretion are related to slow waves has been conducted, further research is needed inspecting the relevance of sleep macro- and microstructure on proposed mechanisms that lead to impaired muscle metabolism. Moreover, the correlation between a significant decline in SWS and the development of sarcopenia observable in elderly requires further investigation. In addition, sleep may become even more important for the metabolic processes during situations challenging muscle homeostasis (e.g., exercise) than baseline physiological conditions $[163,164]$.

\section{Sleep and Body Fat Mass}

Excessive fatness, as observable in obesity, has become a major health problem across the world [166]. An excessive accumulation of body fat mass is often thought to be a consequence of an unhealthy diet and low levels of physical activity, whereas poor and short sleep are rarely considered as risk factors.

Several studies reported correlations between indices of fat mass and insufficient sleep [167-172] consistently across all age groups [173-179]. Interestingly, a trend towards higher BMI with less hours of sleep has been observed in men, whereas the relationship in women has been found to be U-shaped [180], suggesting that the dose-response relationship is influenced by gender. In a large-scale study including 1,024 volunteers, a minimal

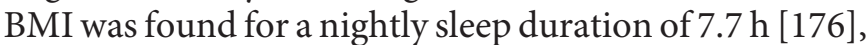
which is in line with the recommended $7 \mathrm{~h}-9$ h sleep/ night for adults [181]. The identification of underlying mechanisms linking sleep to BMI is of current interest and not yet completely resolved. However, endogenous mechanisms such as appetite regulation by hormones and the endocrine control of energy expenditure are likely to be involved [182]. Another potential mechanism how short sleep may lead to weight gain involves the change in food choices or the increased wake time in an obesogenic environment [183], leading to increased energy intake [182]. Most likely, no single pathway fully explains the association between short sleep and high BMI, but rather various mechanisms are simultaneously at play. Jurado-Fasoli et al. [184] observed an association between body fat mass percentage, assessed by DXA, and poor subjective sleep quality in sedentary middle-aged adults, which did not remain significant after including 
sex or sex and age in the model. Neither subjective sleep efficiency nor accelerometer-assessed wake after sleep onset correlated with body fat mass percentage [184]. In contrast, lower sleep efficiency measured by actimetry was found to be associated with higher fat mass assessed by BIA in students [185]. Interestingly, this association differed between men and women. The observation only held true for sleep on workdays in women, and for sleep on weekend days in men. This unexpected difference led to the hypothesis that poor sleep on workdays in women was tightly related to low levels of physical activity on these days. However, poor sleep efficiency in men on free days was observed to occur simultaneously with a higher dietary fat intake [185]. Other studies assessing body composition by BIA found single components of PSQIassessed subjective sleep including sleep latency, sleep disturbances, and daytime dysfunctions to be associated with body fat mass [186]. Similarly, total sleep duration reported on a questionnaire correlated with fat mass assessed by BIA in young athletes [187]. Although the authors do not discuss potentially underlying mechanisms in detail, poor sleep patterns are hypothesized to alter endocrine function [186] towards a pro-fat-deposition hormonal pattern such as increased morning cortisol, which in turn increases the amount of body fat [185, 187].

Rao et al. [188] further linked fat mass to aspects of sleep architecture. BMI, but not the percentage of total body fat mass measured by DXA, was shown to be significantly associated with SWS percentage. As a possible limitation and reason for the lack of a relationship, the authors suggest that abdominal rather than total body fat might be associated with SWS, with only latter examined in this study [188]. Another study aimed to determine gender differences in the context of body composition and sleep patterns [189]. Detailed analyses of sleep architecture revealed a significant negative correlation between SWS percentage and percentage of body fat mass in women but not in men [189]. Apart from SWS, a population-based study found a reduction in REM sleep to be associated with obesity in women [190]. Similar results were obtained in children and teens, showing time spent in REM state to negatively correlate with overweight [191]. Chronic insomnia, which is considered the most prevalent sleep disorder [192] and that is characterized by a lack of sleep or inability to sleep [193], has also been associated with future weight gain $[175,194]$ and obesity $[176,195]$. Moreover, a meta-analysis found that patients with insomnia had a higher risk of suffering from hypertension, hyperglycaemia, and obesity, which are the lead- ing symptoms of the metabolic syndrome [196]. The causes of insomnia as well as its association with an altered body composition are complicated and diverse. Altered secretion profiles of pro-inflammatory cytokines [197], ageing [198], menopause, stressful events, and depression are all contributing factors to the hyperarousal and finally to insomnia [199]. Although the association with obesity is still unclear, it has previously been hypothesized that a hyperactivation of the hypothalamic-pituitary-adrenal (HPA) axis and a dysregulation of hormones that regulate energy homeostasis might be involved [200, 201].

Taken together, poor subjective sleep quality was repeatedly shown to be associated with unfavourable changes in body fat mass. Yet, the underlying mechanisms are insufficiently explored, but appetite regulation, energy expenditure, and secretion of hormones are likely to be contributing aspects. Little is currently known about whether specific sleep stages may have an impact on body fat mass accumulation and further investigations of extended duration are needed, also considering gender as a relevant factor.

\section{Underlying Mechanisms}

In the following paragraphs, we will discuss potential underlying mechanisms linking sleep to excessive fat tissue. An overview of those mechanisms is presented in Figure 1.

\section{Appetite Regulation}

One mechanism relating sleep to excessive accumulation of body fat mass might be the pattern of food intake, which is driven by appetite, regulated by 2 opposing hormones leptin and ghrelin [202].

\section{Leptin}

Leptin is a hormone that is produced by adipocytes and informs the body about its energy status. It has gained special interest in the context of sleep because its secretion follows a circadian rhythm that is further influenced by sleep and fasting $[179,203]$. Under normal conditions, leptin levels increase during sleep until the peak is reached at around the midpoint of sleep followed by a gradual decrease until mid-afternoon [177]. Reduced leptin levels resulting from chronic starvation enhance the drive to eat [204].

Several cross-sectional studies investigating whether there is a correlation between sleep duration and leptin levels revealed inconclusive results. While Knutson et al. [205] did not find a correlation between habitual sleep 
duration assessed by actigraphy, a large population-based study by Taheri et al. [176] revealed that short habitual sleep duration was associated with decreased leptin levels. Along these lines, several studies investigated whether sleep restriction or sleep deprivation affects leptin levels, again revealing conflicting results. Several studies using total sleep deprivation showed a decreased amplitude of the variation of leptin levels over $24 \mathrm{~h}$ [178, 206, 207]. For example, one study found that sleep restriction to $4 \mathrm{~h}$ compared to $12 \mathrm{~h}$ led to a $19 \%$ decrease in the nocturnal amplitude of leptin levels [207]. In contrast, more recent findings observed leptin concentration to either increase in response to experimental sleep restriction [208] or remain unchanged [209]. Constant measurement of leptin levels during $38 \mathrm{~h}$ of wakefulness in a constant routine protocol aimed to disentangle the specific contributions of the endogenous circadian rhythm and behavioural factors such as sleep on leptin levels. Leptin concentrations increased linearly during the period of wakefulness without a modulation by circadian phase, whereas a significant decrease in leptin during recovery sleep has been observed [179].

The contradictory findings about the association of sleep duration and leptin levels may be explained by the fact that leptin is rather a long-term signal [210]; thus, a single night of short sleep does not lead to an immediate decrease in leptin levels. In line with this notion, chronic short sleep, however, is associated with significantly decreased leptin levels. Moreover, sleep loss affects mean leptin levels over $24 \mathrm{~h}$ as well as the amplitude of the leptin secretion profile $[178,206,207]$ rather than morning serum leptin.

Only little research has been conducted on how sleep architecture is associated with the secretion of leptin. Olson et al. [211] focused on the percentage of REM sleep assessed by PSG and its association with leptin levels that were assessed before and after sleep, respectively. They found a higher percentage of REM sleep to be associated with a more pronounced overnight change in leptin, which is likely to contribute to an increased amplitude of $24 \mathrm{~h}$ leptin levels [211]. Based on findings from previous research, the amplitude of leptin concentration better predicts food intake than morning leptin concentration $[212,213]$. Thereby, changes in circulating leptin may represent the link between the previously discussed association of REM sleep percentage with prevalence of overweight reported by Liu et al. [191] and Theorell-Haglöw et al. [190]. In contrast to the percentage of REM sleep, no significant relationship between any NREM sleep stage and changes in leptin levels was observed [211].

Sleep and Body Composition
Ghrelin

Another peptide involved in the regulation of appetite and food intake is ghrelin. Ghrelin is primarily secreted from the stomach and has been shown to increase appetite thereby leading to increased food intake in humans [214]. Under normal conditions, ghrelin secretion follows a circadian and ultradian pulsatile pattern, with the peak of ghrelin concentration occurring during the night [203]. However, this regulation only applies to lean and not obese subjects [203]. Observational studies investigating the association between sleep duration and ghrelin levels mostly showed ghrelin levels to be negatively correlated with sleep duration $[176,215,216]$. Experimental studies however show conflicting results as reviewed by St. Onge [217]. While some studies report an increase in ghrelin in the sleep deprived compared to the control group [218-220], others did not find any differences [221-223]. For instance, in a study where subjects were allowed to stay in bed for $4 \mathrm{~h} /$ night on 2 days followed by a bedtime of $10 \mathrm{~h} /$ night for another 2 days, researchers observed 28\% higher ghrelin levels in the sleep-restricted condition than the $10 \mathrm{~h}$ bedtime condition [219]. Similarly, another study found increased ghrelin levels after one night of total sleep restriction compared to a sleep opportunity of $5 \mathrm{~h}$ using a crossover design. In-between ghrelin levels were observed in the third condition, in which volunteers had the opportunity to sleep for $7.5 \mathrm{~h}$ [218]. Thus, in contrast to leptin, ghrelin seems to be more sensitive to short-term sleep behaviour [176], which is in line with the fact that ghrelin is a rapidly acting hunger signal, whereas leptin is a long-term energy balance parameter [224]. The findings that sleep loss leads to alterations in endocrine levels which control food intake might be part of the link between short sleep and the risk of obesity. However, the conflicting results warrant largescale controlled experiments. Different study regimes, sampling times, participant characteristics, and the complex interplay between hormones may contribute to varying results [182]. Furthermore, increased food intake following sleep curtailment has been consistently reported $[182,217]$. Therefore, factors other than hormonal imbalance should be considered to explain the obesogenic effect resulting from short sleep [182].

\section{Adiponectin}

Adiponectin belongs to the group of adipokines and is specifically secreted by adipocytes, the cells of adipose tissue [225]. It is inversely correlated with the amount of adipose tissue and its concentration has been observed to decrease with the onset of obesity [226]. Recent evidence 
from animal studies promises beneficial effects of adiponectin in terms of weight reduction and improvements in insulin sensitivity [227]. Therefore, the question is whether an intervention may lead to an increase of endogenous serum adiponectin and potentially promote a healthy weight management in humans. As one factor, sleep might modulate adiponectin levels through the HPA axis, which is sensitive to sleep. SWS might be of particular interest since an inhibitory effect of SWS on the HPA axis and subsequently on cortisol secretion has previously been reported [143]. In a study by Fallo et al. [228], administration of glucocorticoids such as hydrocortisone leads to an inhibition of adiponectin secretion in healthy males, supporting the fact that glucocorticoids affect adiponectin levels. Taken together, evidence suggests that experimentally induced enhancement of slow waves could lead to decreased glucocorticoid levels, which in turn results in higher adiponectin levels. However, there are numerous studies showing that glucocorticoid treatment led either to increased blood adiponectin concentrations [229-234] or to no observable effect [235-237]. Nonetheless, the use of distinct types of glucocorticoids and different dosing regimens render results hardly comparable. More standardized research is needed addressing the question of whether glucocorticoid administration modulates adiponectin levels, before conclusions regarding the HPA axis and sleep can be drawn [238]. To our knowledge, there is currently only one study investigating the direct association between sleep and adiponectin levels. In this investigation, experimental sleep restriction only decreased adiponectin levels in women but not in men [239].

\section{Growth Hormone}

Studies investigating how GH secretion is affected by sleep have previously been discussed in the relation to muscle mass. In this context, especially SWS has gained attention since it represents the window of most pronounced GH release [92, 240-242]. Selective SWS disruption by electrical stimulation [243] or natural reduction through ageing has been accompanied by reduced GH secretion [93], whereas SWS stimulation by pharmacological treatment led to increased GH secretion [94]. The following paragraph will discuss the effects of GH secretion on fat mass and whether targeting GH secretion by sleep modulation has the potential to improve body composition. Contrary to the anabolic effects of GH in most tissues (e.g., muscle), $\mathrm{GH}$ is involved in catabolic processes in adipose tissue [244] (see Fig. 3 as an overview of the effects of GH on body tissues). GH secretion in healthy individuals is negatively associated with the mass of adipose tissue, especially visceral adipose tissue [245-248]. Decreased $\mathrm{GH}$ secretion is observed in obese, which manifests as a decline in the mass of GH secreted per burst $[249,250]$. The central mechanism relating $\mathrm{GH}$ to the accumulation of adipose tissue lies in the induction of lipolysis, which forms the catabolic branch of fatty acid metabolism [251]. Lipolysis makes free fatty acids available for use when they are needed as substrates for lipid synthesis [244]. Induction of lipolysis has been shown to reduce adipose tissue mass, thus resulting in body fat mass reduction in both human [252] and animal studies [253]. Numerous studies have evaluated the potential of GH treatment as means to treat obesity [254-259]. There is mounting evidence that a $\mathrm{GH}$-induced reduction in adipose tissue does not ultimately lead to a metabolically healthy tissue, but rather results in an unhealthy lean phenotype [246]. This counterintuitive difference between healthy obese and unhealthy lean needs further investigation and should be taken into account when considering $\mathrm{GH}$ augmentation as a means to improve body composition. It is noteworthy though that enhancing endogenous GH secretion has less adverse effects compared to exogenous GH administration $[256,259]$. Hence, further research is needed investigating the possibility to increase endogenous GH secretion through sleep modulation and the potentially subsequent favourable changes in body fat mass.

\section{Limitations and Implications}

The number of studies investigating the relation between sleep and BMI exceeds studies assessing fat mass directly. Although BMI does not provide information about body mass composition due to its simplicity, it still often is the method of choice to assess someone's overweight or obesity. However, the strong positive correlation between body fat mass and BMI across the general population legitimates its use instead of body fat mass $[37,38,260-263]$. The variety and diversity of potential underlying mechanisms how body fat mass is related to sleep underlines the complexity of this field. Although it is likely that a multitude of mechanisms are involved, one big challenge is to elucidate their individual and causal impact. Furthermore, mechanisms leading to fat mass accumulation are likely to be highly versatile. Apart from molecular mechanisms relating to how ingested food is used and stored in our bodies, the regulation of appetite and satiety already starts beforehand. Moreover, regulation of food intake is not solely mediated by a homeostatic system but also by the hedonic system [264, 265]. The hedonic system refers to the concept that food intake can additionally be driven by the presence of highly palat- 
able food that exert a highly rewarding experience. In the presence of such foods, the hedonic system can even abrogate the control by the homeostatic system [266]. Thus, it is not enough to exclusively focus on the actions of leptin, ghrelin, and other satiety signals to understand the drivers for eating. Further research, which also considers motivational and rewarding aspects of food intake and whether these mechanisms are influenced by sleep, is therefore needed.

Promising results obtained from a single animal study showed that adiponectin deserves further attention [227]. Here, researchers showed that slow wave enhancement inhibited the HPA axis, resulting in decreased cortisol secretion [267]. Thus, adiponectin concentration may change beneficially as well. Yet, there is need for future research directly examining the modulation of adiponectin levels through slow wave manipulation and its longterm consequences on fat tissue turnover. Although here we focus on the effect of sleep on body compositions and the underlying pathways, it should also be mentioned that there is evidence for a reciprocal interaction. One key example of this reciprocal interaction is obstructive sleep apnoea, a serious sleep disorder that causes breathing to repeatedly stop during sleep. While obesity is among the main risk factor for OSA, the disorder itself leads to a disturbed sleep ultimately altering energy balance resulting in further weight gain [268]. The polycystic ovary syndrome (PCOS) is another pathological condition that exemplifies the bidirectional relationship of altered sleep characteristics and body composition mediated by metabolic and endocrine changes. PCOS is an endocrine disorder affecting metabolic and reproductive processes [269]. Besides having a higher tendency to be overweight than the general population, sleep problems are frequently reported in patients with PCOS [270]. Although it is known that overweight may lead to sleep problems, overweight only partly accounts for the sleep problems in PCOS [270]. Various other mechanisms through which PCOS may lead to sleep disorders and disturbances have been proposed, including an upregulation of the HPA axis [271], increased androgen levels [270, 272], and insulin resistance $[198,273,274]$. However, the underlying mechanisms are probably much more complex and numerous, and not all of them are known yet. With OSA and PCOS here we just briefly discussed 2 examples that highlight the complexity of clearly distinguishing between the direction of the relationship between altered sleep characteristics and changes in body composition. To understand the reported associations on a mechanistic level, controlled experimental studies are needed.

Sleep and Body Composition

\section{Sleep and Bone Mass}

Bone tissue is crucial for providing rigidity, strength, and shape and is essential for movement. Although bone tissue is a rigid structure, it undergoes dynamic changes, namely, the 2 processes formation (mediated by osteoblasts) and resorption (mediated by osteoclasts). Maintaining a constant bone mass requires a dynamic homeostasis between these opposing processes. Any imbalance, as it may occur with increasing age, altered sex hormone levels or the use of medication leads to a weakening of bone structure and increases the risk for fractures [275]. Bone health is usually assessed by DXA as bone mineral density (BMD) and bone mineral content (BMC), which both have been shown to decrease with age due to the imbalance in bone turnover [276]. Furthermore, BMD and $\mathrm{BMC}$ are reported to be lower in females compared to males [277], making gender and age factors requiring adjustment. BMD provides information for assessing bone fracture risk, whereas whole-body BMC is mainly heightdependent and not providing information about bone strength [278].

Restorative sleep is likely required to allow bones to recover from the pressure acting on them throughout the day. Yet, the underlying mechanisms how sleep affects bone homeostasis are complex and largely unknown. Evidence that sleep and bone health are related is mainly derived from studies assessing the quality and duration of sleep together with BMD assessments. Both long [279284] and short sleep duration [281, 282, 285-292] have repeatedly been associated with low BMD and osteoporosis. However, a meta-analysis found that only long sleep duration ( $\geq 8 \mathrm{~h} /$ day) was associated with a $22 \%$ higher risk of osteoporosis, while no association between short sleep and osteoporosis was found [293]. Furthermore, some studies found no association between sleep duration and BMD [74, 294]. Additional investigations examined whether subjective sleep quality, assessed by PSQI, was associated with bone health. Here, poor subjective sleep quality was found to negatively correlate with BMC and $\mathrm{BMD}[74,184,295]$. One major limitation of these studies is the subjective report of sleep duration and quality, thereby making the results hardly comparable between individuals. In addition, objective sleep quality assessed by an accelerometer was not associated with any bone health parameter [184]. Taken together, there is currently much inconsistency in this area of research pointing to the need of further research as well as for controlled experiments with objective sleep parameters (e.g., PSG-assessed macro- and microstructure aspects of sleep).

Neuroendocrinology 2022;112:673-701 DOI: $10.1159 / 000518691$ 


\section{Underlying Mechanisms}

The underlying mechanisms on how poor sleep quality and/or sleep duration may negatively affect bone health are likely to be versatile [184]. Several mechanisms linking various sleep variables to bone turnover have been suggested and will be discussed in the following paragraphs. Figure 1 provides a graphical overview of those potential mechanisms.

\section{Bone Turnover Markers}

A useful means to examine mechanisms by which sleep affects bone health are bone turnover markers (BTMs) measurable in blood in response to bone resorption, bone formation, or cytokine function.

Swanson et al. [296] investigated the impact of a combined sleep restriction and circadian disruption intervention on 4 BMTs: C-terminal cross-linked telopeptide of type I collagen (CTX), which is indicative for bone resorption, N-terminal pro-peptide of type I procollagen (P1NP), a biomarker for bone formation, sclerostin, and fibroblast growth factor 23 (FGF-23), 2 biomarkers for osteocyte function. Participants underwent an intervention including sleep restriction to $5.6 \mathrm{~h} /$ night in combination with forced circadian-desynchrony, which was provoked by $28 \mathrm{~h}$-days for 3 weeks. They reported P1NP to be significantly lower post-intervention than baseline levels, with a more pronounced effect in younger subjects ( $<28$ years) than in older subjects ( $>55$ years). A significant increase and decrease in response to the intervention were observed for sclerostin and FGF-23, respectively. While the increase in sclerostin was only observed for the younger group, the change in FGF-23 levels was observable among all participants. CTX was not affected by the intervention [296]. Interestingly, P1NP levels declined significantly from the first day of intervention and stayed at almost constant lower levels during the following 3 weeks [297].

Among BTMs, CXT displays the most robust $24 \mathrm{~h}$ circadian rhythm $[296,298-300]$ with generally higher levels observed in women than in men [301]. However, the shape of the $24 \mathrm{~h}$ profile of bone resorption parameters such as CTX does not seem to be influenced by sex [302, 303], age [302], posture [302], or parathyroid hormone [304]. In addition, fasting has been identified as a factor that diminishes the amplitude of the CTX concentration rhythms but does not change the 24 -h profile [302, 305, 306]. P1NP on the other hand does not seem to follow a clear circadian rhythm [307-309] and is relatively insensitive to food intake [310], thereby rendering P1NP a suitable biomarker for investigating the effect of sleep restric- tion or deprivation. The distinctive sinusoidal rhythm across the $24 \mathrm{~h}$ of a day, as for instance observed in CTX, is likely due to the presence of peripheral oscillators as suggested by the expression of clock genes in bone tissue [311-314]. Sleep restriction or deprivation or the shift of sleep timing as it may occur in night shift work can therefore potentially lead to a disrupted rhythmicity of BTMs and may subsequently result in impaired bone health due to an imbalance between bone formation and bone resorption. Observations made among night shift workers support this mechanism [315, 316], as for instance reported in postmenopausal female rotating-shift nurses that showed lower BMD at lumbar spine and at femoral neck than those that worked daytime shifts [315].

\section{Inflammation}

The presence of an inflammatory microenvironment, especially if persisting over a long time, is known to negatively influence bone metabolism by disturbing the balance between bone-resorbing osteoclasts and bone-forming osteoblasts, finally resulting in bone loss [317]. A system centrally involved in the regulation of bone turnover is the RANKL/OPG system, which was shown to be highly sensitive to inflammation [317]. Binding of RANKL to osteoblasts induces a signalling cascade, ultimately leading to the differentiation of osteoclasts [318]. While under physiological conditions osteoclast differentiation is tightly controlled through the inhibitory effect of OPG, this system is disturbed in an inflammatory response.

Rheumatoid arthritis (RA) is one example for a chronic inflammatory disease, which leads to a constant secretion of pro-inflammatory cytokines and thereby serves as a model to investigate the effect of inflammation on bone mass. The secreted pro-inflammatory cytokines in RA include IL-6, IL-1, IL-17, and TNF- $\alpha$. These cytokines lead to an enhanced osteoclastogenesis, mainly mediated by their activating effect on RANKL [162, 319]. Moreover, besides the secretion of resorption-promoting cytokines, RANKL secretion itself is enhanced. This in turn leads to a change in the RANKL/OPG ratio and ultimately interference with the fine-tuned balance between bone formation and bone resorption [317].

While so far much of the research has focussed on an inherited autoimmune disease, it remains to be elucidated what other factors can cause the presence of a persisting inflammatory bone microenvironment. Noteworthy, very little research has been conducted in the area investigating whether sleep has any influence on inflammation processes in bone tissue. While no human study exists yet, an experiment in rodents found an increased ex- 
pression of IL-1 $\beta$, TNF- $\alpha$, and RANKL in the temporomandibular joint of animals that were paradoxical (REM) sleep-deprived compared to the control group, indicating an impaired bone metabolism [320]. More research is needed to further examine the relevance of inflammation on bone metabolism altered by sleep variables. Potential candidates are IL- 6 and TNF- $\alpha$, and both pro-inflammatory cytokines were previously shown to be increased in healthy young adults who had their sleep restricted to $6 \mathrm{~h}$ per night [321]. Importantly, inflammation is not bad per se and should not be generally thought to interfere with bone health. Inflammatory mediators are part of the normal healing response or are needed as an immune response towards pathogens. However, chronic inflammation or an increase of inflammatory markers over prolonged time periods might negatively affect bone turnover. Consequently, future studies assessing sleep-related changes in inflammation markers and their role in bone turnover should include long-term investigations.

\section{Autonomic Nervous System Activity}

Another potential link between sleep and bone health is the autonomic nervous system (ANS). For instance, short sleep was found to be associated with sympathetic nervous system (SNS) hyperactivity [288], which in turn was shown to favour low bone mass [322]. Likewise, also the second branch of the ANS, the parasympathetic nervous system (PNS), might affect bone metabolism with opposite effects [323]. Concordantly, sectioning PNS fibres in rodents was observed to result in low bone mass [324].

The main neurotransmitter of the SNS is norepinephrine, which exerts its function via $\alpha$ - and $\beta$-adrenergic receptors. Bone cells show mainly an expression of $\beta$-adrenergic receptors and rodent studies showed that daily stimulation of these resulted in increased bone catabolism characterized by enhanced osteoclast formation, a reduction in the function of osteoblasts, and finally in bone loss [325-328]. In addition, selective blockage of these receptors in young mice increased bone-forming activity, ultimately leading to a higher observed bone mass [328-330]. In contrast, PNS activity is suggested to have a favourable influence on bone mass via direct action of acetylcholine on osteoclasts and osteoblasts as well as through the suppressive effect on sympathetic activity on bone receptor levels [331-333]. Sharing neurophysiological and chemical mechanisms, autonomic regulation, and sleep is tightly linked on the anatomical as well as on the physiological level [149]. Transitions be- tween sleep stages are characterized by coincidentally fluctuating ANS activity [334]. The parasympathetic tone increases during $\mathrm{N} 2$ and $\mathrm{N} 3$ sleep compared to wake [335], whereas the sympathetic tone decreases [336]. Moreover, while NREM sleep is clearly characterized by parasympathetic predominance, sympathetic activity dominates during REM sleep [336]. The SNS activity was even shown to exceed the sympathetic activity during wake [337]. Recently, experimental enhancement of SWA by auditory stimulation was shown to increase parasympathetic activity during SWS [149]. SWS-mediated changes in ANS activity are thought to influence several physiological processes including glucose metabolism [338], immune [339], and cognitive functions [340]. Therefore, the characteristic predominance of parasympathetic activity together with low sympathetic tone during SWS may represent a favourable window for bone formation.

\section{IGF-1/GH}

As previously discussed, GH and ultimately IGF-1 secretion are strongly influenced by SWS. However, the importance of GH is not restricted to muscle tissue only but is likewise involved in growth mechanisms in other tissues, including bone (see Fig. 3 for an overview). In experimental studies, administration of both, GH and IGF1 , was found to stimulate the growth of longitudinal bones in animals and humans by direct action [341, 342] as well as indirectly by increasing the production of IGF1 [342, 343]. Additional evidence supporting the critical effect of GH on bone mass comes from studies investigating the effects of GHD [344]. It was shown that a lack of $\mathrm{GH}$ and simultaneous low levels of IGF-1 in mice with mutation in the GHRH receptor were associated with osteopenia and reduced cortical bone mass. Exogenously administered IGF-1 did almost completely reverse the negative effect on bone growth [344]. Moreover, in patients suffering from adult growth hormone deficiency, treatment with GH resulted in an increase of BMD [345, 346]. Therefore, when present at subphysiological levels, $\mathrm{GH}$ administration seems to be beneficial in terms of promoting bone health and increasing BMD. However, whether this effect is of great importance under physiological levels remains to be elucidated. Nevertheless, evidence from experimental studies in osteoporotic subjects as well as in patients with bone fractures revealed a significant positive effect of GH or IGF-1 administration on bone health [347, 348]. IGF-1 administration in healthy and osteoporotic females was found to increase bone formation in several studies, including different dosing reg- 
imens and durations varying from 6 days to 9 months [349-354]. Since GH/IGF-1 is known to be involved in mechanisms that are impaired in delayed or failed bone fracture healing, several clinical trials investigated the effect of GH/IGF-1 administration on fractured bone healing. They reported increased BMD, better functional recovery, as well as increased bone strength [354-356]. Based on experiments that found a significant association between SWS and GH secretion [91-94], sleep modulation may support bone mass preservation in osteoporotic people as well as in the healing process following a bone fracture.

\section{Leptin}

Although leptin is primarily known for its central role in the regulation of energy homeostasis, its involvement in bone metabolism receives increasing attention. First evidence showed that leptin-deficient mice had higher vertebral trabecular bone mass than wild-type mice [357]. Over the years, further evidence emerged that leptin acts centrally as well as peripherally to control bone mass [358-361]. This has risen the question on how the communication between cells in the brain and bone cells is possible. Therefore, a mice parabiosis model was used to determine whether the factor leading to low bone mass phenotype could be exchanged via circulation or whether it was of neural origin. Seeing that only the animals that got leptin delivered into the third cerebral ventricle did show low bone mass, the mediator was suggested to be a signal of neural nature [357]. As already discussed in relation to body fat mass, leptin levels have repeatedly been shown to be sensitive to short sleep as well as to single sleep stages $[176,178,206,207]$. Therefore, further research investigating leptin concentration in response to sleep in general and to the modulation of sleep, more specifically, should consider that leptin is also crucially involved in bone metabolism apart from its central role in energy homeostasis.

\section{Limitations and Implications}

Although many studies only focused on total sleep duration or sleep quality so far, some pathways have been suggested, which are likely involved in bone turnover and which are affected by a variety of sleep parameters. Activity of the ANS, for example, may play an important role in bone metabolism as sympathetic activity was shown to dominate during REM sleep [337] and to be associated with bone resorption [325-328]. Moreover, BTMs' characteristic for bone resorption displays a peak in the second half of the night when REM sleep predominates
[302]. PNS as counterpart of the SNS predominates during SWS [335] and was proven beneficial for bone formation [331]. Taken together, either selectively intensifying NREM sleep (SWS enhancement) or decreasing the proportion of REM sleep without changing total sleep duration may represent potential approaches to shift the activity of the nervous system more towards parasympathetic activity and subsequently the balance of bone metabolism more towards bone formation. While methods to enhance and intensify SWA exist and have previously already been discussed, suppression of REM sleep is a less typical experimental approach but is a commonly observable phenomenon in people taking antidepressants [362]. Therefore, further investigations are needed focusing on the association between sleep architecture and bone health in more detail. Identification of a specific sleep micro- or macrostructural feature that is especially critical in bone metabolism may represent a target for selective modulation in order to increment parasympathetic activity during sleep.

Moreover, leptin and GH/IGF-1 are likely to be further mechanisms involved in the link between sleep and bone health. While balanced leptin concentration importantly contributes to a healthy bone metabolism [357-361], dysregulated leptin levels as a consequence of short sleep $[178,206,207]$ may negatively affect bone mass. However, whether the modulations in leptin levels caused by changes in sleep duration are relevant for bone turnover needs to be further investigated. The relevance of GH/ IGF-1, on the other hand, has previously been shown to be of clinical importance in the pathology of osteoporosis [349-354], after bone fractures [354-356], and is likely to affect GH secretion [91-94]. Further controlled studies over an extended period are required to explore whether GH levels can be increased to clinically significant levels by sleep modulation and whether this increase translates into improved BMD.

\section{Metabolic System under Challenge: The Role of Sleep}

The previous paragraphs on the role of sleep in metabolic processes mainly summarized current evidence under resting conditions. Yet, sleep might become specifically important at times when the metabolic system is challenged, such as induced by physical exercise, during a weight reduction diet, or when bones are fractured. Here, we focus on the potential interplay of sleep with these challenges. 
Promoting Muscle Anabolism: Physical Exercise and the Role of Sleep

Physical exercise, especially resistance training, is widely accepted as the main strategy to induce muscle hypertrophy and improve musculoskeletal health [363, 364]. A single bout of resistance exercise has consistently been shown to trigger muscle protein synthesis, resulting in a net protein balance when combined with protein intake $[365,366]$. Resistance exercise enhances the ability for skeletal muscle cells to sense amino acids [367], ensuring an adequate rise in postprandial muscle protein synthesis and accretion of muscle tissue when the exercise regimen is sufficiently repeated over time [368]. Nutrition and muscle contraction work in synergy to augment post-exercise increases in muscle protein synthesis and mass on the longer term, but the influence of sleep has been neglected so far.

Intriguingly, a recent study showed that short-term sleep deprivation leads to lower rates of myofibrillar protein synthesis in the basal, non-exercised state. However, when subjects performed high-intensity interval training during this 5-day period of sleep deprivation, myofibrillar protein synthesis rates were maintained at control levels, suggesting that high-intensity muscle contractions can overcome the negative effects of sleep deprivation on muscle architecture [369]. In line with these data, a 96-h period of sleep deprivation in rats resulted in $~ 5 \%$ muscle atrophy over the course of 8 weeks, while resistance training in the form of weighted ladder training attenuated the reduction in muscle fibre cross-sectional area [370].

Given the increasing prevalence of inadequate sleep in modern societies, future efforts should be directed to better understanding the mechanisms underlying the profound effects of sleep deprivation on basal muscle protein synthetic rates. In the long run, the gained knowledge could be used to optimize interventions to reduce the negative effects of sleep deprivation on muscle health. For instance, overnight sleep is the longest post-absorptive phase across the $24 \mathrm{~h}$ of a day and emerging evidence suggests that pre-sleep protein intake can enhance positive effects on muscle remodelling both acutely [371-374] and in the longer term $[375,376]$. Hence, potential exciting areas of interest include the optimization of pre-sleep protein beverages in terms of amino acid composition and absorbability that improve net protein balance in sleep-restricted situations. Additionally, given the profound effects of muscular contractions on muscle protein synthesis, future research should focus on the promotion of exercise regimens that are tolerable in a sleep-deprived state.

Sleep and Body Composition
The Role of Sleep for Successful Weight Loss and Weight Loss Maintenance

Given that both short sleep duration and obesity are increasingly prevalent in modern societies, investigating the importance of sleep for weight loss is of high interest for public health [377]. Subjectively reported sleep quality and quantity prior to weight loss interventions were shown to be associated with the success of the intervention and subsequent maintenance of lost weight [378]. Furthermore, worse sleep quality at 6 months after the intervention decreased the likelihood of successful weight loss or maintenance of lost weight at 18 months [378]. Among the objectively actigraphy-assessed sleep parameters, only sleep duration significantly correlated with the amount of maintained weight loss [379]. Comparing a group of subjects undergoing calorie restriction (CR) to another group in which CR was combined with sleep restriction (decreased habitual sleep duration of $1 \mathrm{~h}$ per day on 5 days/ week), this study aimed to determine whether the association between sleep duration and weight loss can also be found in an experimental design. Although both groups lost similar amounts of weight, the proportion of weight lost as fat was significantly higher in the CR group that had an unchanged sleep duration [380]. Another study with a daily calorie deficit of $600-700 \mathrm{kcal} /$ day over a period of $15-24$ weeks led to a mean weight loss of $4.5 \pm 3.9 \mathrm{~kg}$. Interestingly, subjectively reported sleep duration at the beginning of the experiment was found to be positively correlated with the proportion of weight loss coming from fat stores [381]. Although studies investigating the association between sleep duration and the success of weight loss predominate, results from a study by Verhoef et al. [382] also propose the presence of a relationship in the opposite direction. Here, changes in sleep duration were assessed during a 3-month weight loss intervention in obese volunteers. Subjectively classified short sleepers at baseline, who successfully lost weight, had significantly increased their sleep duration with weight loss. These results imply a bidirectional relationship between sleep duration and weight loss and both seem to benefit from each other [382]. Taken together, sleep may represent a modifiable factor that should be considered in weight loss programs and that may additionally facilitate the success of the intervention. Yet, more research is needed to identify which sleep aspects and underlying mechanisms efficiently support weight loss.

\section{The Role of Sleep in Bone Fracture Healing}

Bone fractures are among the most common injuries of the musculoskeletal system and thus affect a great 
number of people [383]. Essentially, the demographic shift towards an ageing population contributes to the increasing prevalence of fragility fractures [384]. Although bone tissue has a unique capacity for repair, a substantial proportion of fractures result in non-union or delayed healing [385]. Thus, several factors have been identified that determine the chance of successful healing response: fracture type, age, treatment, mediation, alcohol, and smoking [386]. Evidence from animal studies showed that sleep deprivation in rats resulted in a decreased BMD, decreased osteogenesis, and impaired bone mineralization [387], which may indicate that sleep is another factor determining risk for incomplete or delayed healing. A rodent study inducing femur fracture together with experimentally induced sleep deprivation supports the central role of sleep for the healing process as sleep deprivation was found to delay bone fracture healing and significantly increase levels of the pro-inflammatory cytokines IL- $1 \beta$ und TNF- $\alpha$ [388], which are in line with findings from previous studies [389]. Treatment with the anti-inflammatory drug trehalose substantially mitigated the negative effects of sleep deprivation on bone recovery [388]. Taken together, observations from rodent studies imply that sleeping enough is crucial during bone fracture recovery. However, the fact that evidence is restricted to animal studies represents a major limitation to the relationship between sleep and human bone healing. Therefore, further research in humans is needed to translate the significance of this observation to human bone fractures. Nevertheless, as experimentally induced fractures in humans are not feasible, epidemiological studies recruiting patients with fractures should be considered to investigate the role of sleep on the healing process and success.

\section{Limitation of the Present Work and Implications for Further Research}

For all reviewed body composition parameters, muscle mass, bone mass, and body fat mass, a link to sleep has previously been documented. Yet, there have been several limitations that render definite conclusions difficult.

First, in most of the presented studies, body composition, sleep, or both were assessed with inaccurate methods. Therefore, many sleep studies collected rather anthropometric than body composition data or several studies that accurately measured body composition with DXA or BIA assessed sleep solely with subjective sleep questionnaires such as the PSQI. Furthermore, previous work has often only been limited to total sleep duration and its association with symptoms or diseases. Thus, accurately examining body composition by DXA and acquiring sleep data via PSG, which allows the identification of sleep architecture even on a topographical level when assessed with high-density EEG, may have a promising potential for the identification of relationships between sleep and body composition.

Second, the number of observational studies exceeded the number of controlled experiments by far. Investigating the associations between sleep variables and body composition parameters or specific molecules does not give any information about a causal relationship. To draw valid conclusions about mechanisms, more controlled experimental studies that manipulate sleep are needed. There is evidence for some pathways, suggesting that the amount of SWS is of particular importance. Therefore, selective enhancement of slow waves and increasing SWS percentage over the course of a night without changing total sleep duration represents an interesting and promising approach for further pursuit. In the early years of this research field, mainly pharmacological approaches were used, which were shown to effectively decrease daytime sleepiness in sleep-restricted individuals [267]. However, since pharmacological approaches entail the problems of tolerance and dependence, over the years additional non-invasive methods have been established. Promising avenues to modulate slow waves include slow oscillatory transcranial direct current stimulation [263], transcranial magnetic stimulation [270], and sensory stimuli such as auditory (closed-loop) stimulation [390]. To date, auditory stimulation represents the most promising approach because of its low costs, safety, scalability for long term, and mobile use in ambulatory studies as well as artefact-free EEG recordings [391]. Even though this method is still in its infancy, some well-controlled in-lab studies exist, which showed its potential in boosting slow waves along with modifications in memory consolidation, cortisol levels [95], and immune supportive responses [95]. Single session glucose tolerance and $\mathrm{GH}$ levels in healthy young adults were not effectively modulated so far $[95,392]$. However, further research over longer time periods and in populations/situations of increased metabolic demand (e.g., elderly, athletes, and obese) is essential to evaluate its potential to modulate certain metabolic pathways. Finding a means to modulate sleep in such a way that it has a beneficial consequence on body composition is a potential breakthrough in the treatment of various disabling diseases and concurrently would also massively decrease the burden on health costs. Furthermore, we need to con- 
sider that various research models including in vitro studies, different in vivo animal studies, and well-controlled human laboratory studies up to large-scale cohort assessments and meta-analyses provide different levels of evidence (e.g., mechanistic insights and societal impact). Therefore, an interdisciplinary approach leveraging on studies that span different research models and techniques will be important to establish a comprehensive understanding of the role of sleep in metabolism from a mechanistic to a societal perspective.

Third, even though sleep restriction/deprivation studies primarily define the role of sleep in certain processes, a complete separation of circadian influences is not possible since these processes are not completely independent [393]. The inclusion of circadian control parameters and studies that subtly alter parameters of sleep (e.g., enhance amount of deep sleep, modulate REM sleep) instead of modifying sleep duration could help to disentangle the direct role of specific sleep characteristics (rather than indirect changes over circadian modifications) in metabolism.

Finally, while this review summarizes a collection of publications showing links between sleep and body compositions or metabolic processes (implied in body composition), it is largely unknown whether prolonged changes of metabolic processes through sleep modification/changes will translate into significant body composition adaptations. Moreover, the effect of sleep or sleep modulation may be different under baseline conditions and when the metabolic systems are challenged or in a pathological state. Studies identifying the translational potential of metabolic changes through sleep in different contexts will be of utmost importance and require wellcontrolled, long-term trials including sleep modulation, molecular assessments, and accurate sleep and body composition tracking. Long-term assessment and modulation of sleep represent a challenge as these sleep studies are costly and time-consuming for the experimenter and the participants. Nevertheless, the recent development of research-grade, mobile PSG, and sleep modulation systems allows for accurate in-home assessment and modulation of sleep [391] and opens up new possibilities to perform these long-term trials.

\section{Concluding Remarks}

Unhealthy body composition such as an excessive accumulation of adipose tissue considerably impairs overall health. However, while mainly diet and the lack of physi- cal activity seem to cause excessive body fat, sleep is much less seen as a causal risk factor. Similar to muscle mass and bone metabolism, sleep has not received its deserved attention so far.

Here we aimed to provide a review covering the evidence in the field of sleep and body composition parameters including muscle mass, body fat mass, and bone tissue. In addition, we investigated potential mechanisms how sleep architecture, sleep duration, and sleep oscillations may critically influence human body composition. The identification of mechanisms how sleep is associated with changes in body composition represents a target for modulation, thereby promising beneficial consequences for general human health. Some mechanisms that could potentially link sleep and body composition have already been identified. Interestingly, among the described pathways, GH was found to be involved in the homeostasis of all discussed body composition parameters and has been strongly linked to sleep, specifically SWS (see Fig. 3). Therefore, SWS seems to play a key role in connecting sleep to body composition and should be a focus of well-controlled future studies. Specifically, its importance under baseline physiological and under pathological conditions in relation to sleep is of fundamental interest.

The identification of sleep parameters that critically impact key regulators of either type of body mass has a great potential as a target for new treatment options for diseases and disorders related to unfavourable body composition. As shown with the example of obesity, it is not only the condition itself but the numerous disabling comorbidities making obesity a global major health problem. Although muscle atrophy and decreased bone mass affect less people than an unhealthy body fat distribution, both changes in muscle and bone mass may lead to further comorbidities as well. We therefore argue that further research is needed investigating how the modulation of sleep (e.g., sleep oscillations and sleep stages) can positively affect human health through a favourable body composition. Well-controlled, long-term studies in humans and animal models are required to make conclusive statements.

\section{Acknowledgments}

All authors thank their trainees, collaborators, and mentors for the expiring exchanges and dialogues on the thematic of this review. A special thanks goes to Dr. Christine Blume for an in-depth feedback on the manuscript. 


\section{Statement of Ethics}

An ethics statement is not applicable because this review is based exclusively on published literature.

\section{Conflict of Interest Statement}

The authors have no conflicts of interest to declare.

\section{Funding Sources}

The corresponding author Caroline Lustenberger is supported by the Swiss National Science Foundation (PZ00P3_179795).

\section{Author Contributions}

F.M.S., S.H., G.D., and C.L. took part in conceptualization of this review. F.M.S. wrote the first draft of the manuscript. S.H., G.D., and C.L. reviewed and edited the manuscript. All authors revised the manuscript critically for important intellectual content and approved this version of the manuscript to be published.

\section{Data Availability Statement}

Data availability is not applicable to this article as no datasets were generated or analyzed for this review article.

\section{References}

1 Eugene AR, Masiak J. The neuroprotective aspects of sleep. MEDtube Sci. 2015 Mar;3(1): $35-40$

2 Underwood E. Sleep: the brain's housekeeper? Science. 2013 Oct 18;342(6156):301.

3 Alhola P, Polo-Kantola P. Sleep deprivation: impact on cognitive performance. Neuropsychiatr Dis Treat. 2007 Oct;3(5):553-67.

4 Puentes-Mestril C, Roach J, Niethard N, Zochowski M, Aton SJ. How rhythms of the sleeping brain tune memory and synaptic plasticity. Sleep. 2019 Jul 8;42(7):zsz095

5 Tononi G, Cirelli C. Sleep function and synaptic homeostasis. Sleep Med Rev. 2006 Feb; 10(1):49-62.

6 Smith C. Sleep states, memory processes and synaptic plasticity. Behav Brain Res. 1996 Jun; 78(1):49-56.

7 Walker MP, Stickgold R. Sleep-dependent learning and memory consolidation. Neuron. 2004 Sep 30;44(1):121-33

8 Karni A, Tanne D, Rubenstein BS, Askenasy JJ, Sagi D. Dependence on REM sleep of overnight improvement of a perceptual skill. Science. 1994;265:679.

9 Smith C, MacNeill C. Impaired motor memory for a pursuit rotor task following stage 2 sleep loss in college students. J Sleep Res. 1994 Dec;3(4):206-13.

10 Stickgold R, James L, Hobson JA. Visual discrimination learning requires sleep after training. Nat Neurosci. 2000 Dec;3(12):12378.

11 Walker MP. A refined model of sleep and the time course of memory formation. Behav Brain Sci. 2005 Feb;28(1):51-64; discussion 64-104.

12 Walker MP, Brakefield T, Morgan A, Hobson JA, Stickgold R. Practice with sleep makes perfect: sleep-dependent motor skill learning. Neuron. 2002 Jul 3;35(1):205-11.

13 Siegel JM. The REM sleep-memory consolidation hypothesis. Science. 2001 Nov 2; 294(5544):1058-63.
14 Besedovsky L, Lange T, Born J. Sleep and immune function. Pflügers Arch. 2012;463(1): 121-37.

15 Jackson CL, Redline S, Emmons KM. Sleep as a potential fundamental contributor to disparities in cardiovascular health. Annu Rev Public Health. 2015 Mar 18;36:417-40.

16 Van Cauter E, Holmbäck U, Knutson K, Leproult R, Miller A, Nedeltcheva A, et al. Impact of sleep and sleep loss on neuroendocrine and metabolic function. Horm Res Paediatr. 2007; $67(1): 2$.

17 Baumgartner RN. Body composition in healthy aging. Ann N Y Acad Sci. 2000;904: 437.

18 Goodpaster BH, Park SW, Harris TB, Kritchevsky SB, Nevitt M, Schwartz AV, et al. The loss of skeletal muscle strength, mass, and quality in older adults: the health, aging and body composition study. J Gerontol A Biol Sci Med Sci. 2006 Oct;61(10):1059-64.

19 Colón CJP, Molina-Vicenty IL, Frontera-Rodríguez M, García-Ferré A, Rivera BP, Cintrón-Vélez G, et al. Muscle and bone mass loss in the elderly population: advances in diagnosis and treatment. J Biomed. 2018:3:40-9.

20 Staab JS, Smith TJ, Wilson M, Montain SJ, Gaffney-Stomberg E. Bone turnover is altered during $72 \mathrm{~h}$ of sleep restriction: a controlled laboratory study. Endocrine. 2019 Jul;65(1): 192-99.

21 Petrov ME, Whisner CM, Mahmood TM, Castillo LF, Richardson J, Gupta R. 0252 actigraphic sleep is associated with bone mineral density and bone turnover in young adults. Sleep. 2018 Apr;41(Suppl 1):A97-8.

22 Kim K, Shin D, Jung GU, Lee D, Park SM. Association between sleep duration, fat mass, lean mass and obesity in Korean adults: the fourth and fifth Korea National Health and nutrition examination surveys. J Sleep Res. 2017 Aug;26(4):453-60.

23 Scheja L, Heeren J. The endocrine function of adipose tissues in health and cardiometabolic disease. Nat Rev Endocrinol. 2019 Sep;15(9): $507-24$.

24 Khaodhiar L, McCowen KC, Blackburn GL. Obesity and its comorbid conditions. Clin Cornerstone. 1999;2(3):17-31.

25 O'Brien PD, Hinder LM, Callaghan BC, Feldman EL. Neurological consequences of obesity. Lancet Neurol. 2017 Jun;16(6):46577.

26 Sandri M. Protein breakdown in muscle wasting: role of autophagy-lysosome and ubiquitin-proteasome. Int J Biochem Cell Biol. 2013 Oct;45(10):2121-9.

27 Arango-Lopera VE, Arroyo P, Gutiérrez-Robledo LM, Perez-Zepeda MU, Cesari M. Mortality as an adverse outcome of sarcopenia. ) Nutr Heal Aging. 2013 Mar;17(3):259-62.

28 Pahor M, Kritchevsky S. Research hypotheses on muscle wasting, aging, loss of function and disability. J Nutr Heal Aging. 1998;2(2):97100.

29 Sirola J, Kröger H. Similarities in acquired factors related to postmenopausal osteoporosis and sarcopenia. J Osteoporos. 2011;2011: 536735.

30 Kanis JA. Osteoporosis III: diagnosis of osteoporosis and assessment of fracture risk. Lancet. 2002 Jun;359(9321):1929-36.

31 Möckel L. Risk of falls in patients with low bone mineral densitySturzrisiko bei Patienten mit niedriger Knochendichte. Z Gerontol Geriatr. 2020 Sep 3. Epub ahead of print.

32 Janssen I, Shepard DS, Katzmarzyk PT, Roubenoff R. The healthcare costs of Sarcopenia in the United States. J Am Geriatr Soc. 2004 Jan;52(1):80-5.

33 Hernández-Reyes A, Cámara-Martos F, Molina-Luque R, Romero-Saldanã M, MolinaRecio G, Moreno-Rojas R. Changes in body composition with a hypocaloric diet combined with sedentary, moderate and high-intense physical activity: a randomized controlled trial. BMC Womens Health. 2019 Dec 27;19(1):167. 
34 Correa-Rodríguez M, Rueda-Medina B, González-Jiménez E, Schmidt-RioValle J. Associations between body composition, nutrition, and physical activity in young adults. Am J Hum Biol. 2017 Jan;29(1).

35 Imboden MT, Welch WA, Swartz AM, Montoye AH, Finch HW, Harber MP, et al. Reference standards for body fat measures using GE dual energy x-ray absorptiometry in Caucasian adults. PLoS One. 2017 Apr 7;12(4): e0175110.

36 Loftin M, Nichols J, Going S, Sothern M, Schmitz KH, Ring K, et al. Comparison of the validity of anthropometric and bioelectric impedance equations to assess body composition in adolescent girls. Int J Body Compos Res. 2007;5(1):1-8.

37 Gallagher D, Visser M, Sepúlveda D, Pierson RN, Harris T, Heymsfieid SB. How useful is body mass index for comparison of body fatness across age, sex, and ethnic groups? Am J Epidemiol. 1996 Feb 1;143(3):228-39.

38 Jackson AS, Stanforth PR, Gagnon J, Rankinen T, Leon AS, Rao DS, et al. The effect of sex, age and race on estimating percentage body fat from body mass index: the heritage family study. Int J Obes. 2002 Jun;26(6):78996.

39 Borbély AA. A two process model of sleep regulation. Hum Neurobiol. 1982;1(3):195-204.

40 Borbély AA, Daan S, Wirz-Justice A, Deboer $\mathrm{T}$. The two-process model of sleep regulation: a reappraisal. J Sleep Res. 2016 Apr;25(2): $131-43$.

41 Achermann P, Borbély AA. Sleep homeostasis and models of sleep regulation. In: Principles and practice of sleep medicine. 5th ed. 2010. p. 431-44.

42 Deboer T. Sleep homeostasis and the circadian clock: do the circadian pacemaker and the sleep homeostat influence each other's functioning? Neurobiol Sleep Circadian Rhythms. 2018 Mar 1;5:68-77.

43 Cellini N, Mednick SC. Stimulating the sleeping brain: current approaches to modulating memory-related sleep physiology. J Neurosci Methods. 2019 Mar 15;316:125-36.

44 AlDabal L, BaHammam AS. Metabolic, endocrine, and immune consequences of sleep deprivation. Open Respir Med J. 2011;5:31-43.

45 Faraut B, Boudjeltia KZ, Vanhamme L, Kerkhofs M. Immune, inflammatory and cardiovascular consequences of sleep restriction and recovery. Sleep Med Rev. 2012 Apr;16(2) $137-49$.

46 Leproult R, Van Cauter E. Role of sleep and sleep loss in hormonal release and metabolism. Endocr Dev. 2010;17:11-21.

47 Van Cauter E, Spiegel K, Tasali E, Leproult R. Metabolic consequences of sleep and sleep loss. Sleep Med. 2008 Sep;Suppl 1:S23-8

48 Jung R, Berger W. Fiinfzig Jahre EEG Hans Bergers Entdeekung des Elektrenkephalogramms und seine ersten Befunde 1924-1931; 1979.

49 Carskadon MA, Dement WC. Normal human sleep: an overview. In: Principles and practice of sleep medicine. St. Louis: Elsevier Saunders; 2005.

50 Hirshkowitz M. Normal human sleep: an overview. Med Clin North Am. 2004 May; 88(3):551-65.

51 Steriade M. Corticothalamic resonance, states of vigilance and mentation. Neuroscience. 2000;101(2):243-76.

52 Herman JH, Barker DR, Roffwarg HP. Similarity of eye movement characteristics in REM sleep and the awake state. Psychophysiology. 1983 Sep;20(5):537-43.

53 Craig Heller H. Secrets of sleep science: from dreams to disorders. 2013. p. 178

54 Li J, Vitiello MV, Gooneratne NS. Sleep in normal aging. Sleep Med Clin. 2018 Mar; 13(1):1-11.

55 Mander BA, Winer JR, Walker MP. Sleep and human aging. Neuron. 2017 Apr 1;94(1):1936.

56 Carskadon MA, Brown ED, Dement WC. Sleep fragmentation in the elderly: relationship to daytime sleep tendency. Neurobiol Aging. 1982;3(4):321-7.

57 Carskadon M, Dement W, Chapter 2: normal human sleep -an overview. Psychol Med. 2011. 16-26.

58 Rundo JV, Downey R 3rd. Polysomnography. Handb Clin Neurol. 2019;160:381-92.

59 Marino M, Li Y, Rueschman MN, Winkelman JW, Ellenbogen JM, Solet JM, et al. Measuring sleep: accuracy, sensitivity, and specificity of wrist actigraphy compared to polysomnography. Sleep. 2013 Nov 1;36(11): 1747-55.

60 Morgenthaler TI, et al. Practice parameters for the clinical evaluation and treatment of circadian rhythm sleep disorders: an American Academy of Sleep Medicine report. Sleep. 2007 Nov 1;30(11):1445-59.

61 Buysse DJ, Reynolds CF, Monk TH, Berman SR, Kupfer DJ. The Pittsburgh sleep quality index: a new instrument for psychiatric practice and research. Psychiatry Res. 1989 May; 28(2):193-213.

62 Katz LD, Glickman MG, Rapoport S, Ferrannin E, DeFronzo RA. Splanchnic and peripheral disposal of oral glucose in man. Diabetes. 1983 Jul;32(7):675-9.

63 Argilés JM, Campos N, Lopez-Pedrosa JM, Rueda R, Rodriguez-Mañas L. Skeletal muscle regulates metabolism via interorgan crosstalk: roles in health and disease. J Am Med Dir Assoc. 2016 Sep 1;17(9):789-96.

64 Hawley JA, Lundby C, Cotter JD, Burke LM. Maximizing cellular adaptation to endurance exercise in skeletal muscle. Cell Metab. 2018 May 1;27(5):962-76.

65 Janssen I, Heymsfield SB, Wang ZM, Ross R. Skeletal muscle mass and distribution in 468 men and women aged 18-88 yr. J Appl Physiol. 2000 Jul;89(1):81-8.

66 Landi F, Liperoti R, Russo R, Giovannini S, Tosato M, Capoluongo E, et al. Sarcopenia as a risk factor for falls in elderly individuals: results from the ilSIRENTE study. Clin Nutr. 2012 Oct;31(5):652-8.
67 Xue QL, Walston JD, Fried LP, Beamer BA. Prediction of risk of falling, physical disability, and frailty by rate of decline in grip strength: the women's health and aging study. Arch Intern Med. 2011 Jun 27;171(12):111921.

68 Dufour AB, Hannan MT, Murabito JM, Kiel DP, McLean RR. Sarcopenia definitions considering body size and fat mass are associated with mobility limitations: the framingham study. J Gerontol A Biol Sci Med Sci. 2013 Feb; 68(2):168-74.

69 Marsh AP, Rejeski WJ, Espeland MA, Miller ME, Church TS, Fielding RA, et al. Muscle strength and $\mathrm{BMI}$ as predictors of major mobility disability in the lifestyle interventions and independence for elders pilot (LIFE-P). J Gerontol A Biol Sci Med Sci. 2011 Dec;66(12): 1376-83.

70 Nam GE, Han K, Kim DH, Lee JH, Seo WH. Sleep duration is associated with body fat and muscle mass and waist-to-height ratio beyond conventional obesity parameters in Korean adolescent boys. J Sleep Res. 2017 Aug 26(4):444-52.

71 Chien MY, Wang LY, Chen HC. The relationship of sleep duration with obesity and sarcopenia in community-dwelling older adults. Gerontology. 2015;61(5):399-406.

72 Buchmann N, Spira D, Norman K, Demuth I, Eckardt R, Steinhagen-Thiessen E, et al. Sleep, muscle mass and muscle function in older people. Dtsch Arztebl Int. 2016;113(15):253.

$73 \mathrm{Hu}$ X, Jiang J, Wang H, Zhang L, Dong B, Yang M. Association between sleep duration and sarcopenia among community-dwelling older adults. Medicine. 2017 Mar;96(10): e6268.

74 Lucassen EA, de Mutsert R, le Cessie S, Appelman-Dijkstra NM, Rosendaal FR, van Heemst $\mathrm{D}$, et al. Poor sleep quality and later sleep timing are risk factors for osteopenia and sarcopenia in middle-aged men and women: the NEO study. PLoS One. 2017 May 1;12(5): e0176685.

75 Piovezan RD, Abucham J, dos Santos RV, Mello MT, Tufik S, Poyares D. The impact of sleep on age-related sarcopenia: Possible connections and clinical implications. Ageing Res. 2015 Sep 1;23:210-20.

76 Chen Y, Cui Y, Chen S, Wu Z. Relationship between sleep and muscle strength among Chinese university students: a cross-sectional study. J Musculoskelet Neuronal Interact. 2017 Dec;17(4):327-33.

77 Fu L, Yu X, Zhang W, Han P, Kang L, Ma Y, et al. The relationship between sleep duration, falls, and muscle mass: a cohort study in an elderly Chinese population. Rejuvenation Res. 2019 Oct;22(5):390-8.

78 Rennie MJ. Muscle protein turnover and the wasting due to injury and disease. Br Med Bull. 1985 Jul;41(3):257-64.

79 Kant GJ, Genser SG, Thorne DR, Pfalser JL, Mougey EH. Effects of 72 hour sleep deprivation on urinary cortisol and indices of metabolism. Sleep. 1984;7(2):142-6. 
80 Nedeltcheva AV, Kilkus JM, Imperial J, Schoeller DA, Penev PD. Insufficient sleep undermines dietary efforts to reduce adiposity. Ann Intern Med. 2010 Oct 5;153(7):435-41.

81 Piovezan RD, Abucham J, dos Santos RVT, Mello MT, Tufik S, Poyares D. The impact of sleep on age-related sarcopenia: possible connections and clinical implications. Ageing Res Rev. 2015 Sep;23(Pt B):210-20.

82 Veldhuis JD, Iranmanesh A. Physiological regulation of the Human Growth Hormone (GH)-Insulin-Like Growth Factor Type I (IGF-I) axis: predominant impact of age, obesity, gonadal function, and sleep. Sleep. 1996 Dec;19(Suppl 10):S221-4.

83 McKinnell IW, Rudnicki MA. Molecular mechanisms of muscle atrophy. Cell. 2004; 119(7):P907-10.

84 Gunawardane K, Krarup Hansen T, Sandahl Christiansen J, Lunde Jorgensen JO. Normal physiology of growth hormone in adults. 2000.

85 Yarasheski KE, Campbell JA, Smith K, Rennie MJ, Holloszy JO, Bier DM. Effect of growth hormone and resistance exercise on muscle growth in young men. Am J Physiol Endocrinol Metab. 1992 Mar;262(3):E261-7.

86 Taaffe DR, Pruitt L, Reim J, Hintz RL, Butterfield G, Hoffman AR, et al. Effect of recombinant human growth hormone on the muscle strength response to resistance exercise in elderly men. J Clin Endocrinol Metab. 1994 Nov;79(5):1361-6.

87 Yarasheski KE, Zachwieja JJ, Campbell JA, Bier DM. Effect of growth hormone and resistance exercise on muscle growth and strength in older men. Am J Physiol. 1995 Feb;268(2 Pt 1):E268-76

88 Velloso CP. Regulation of muscle mass by growth hormone and IGF-I. Br J Pharmacol. 2008 Jun;154(3):557-68.

89 Rudman D, Kutner MH, Rogers CM, Lubin MF, Fleming GA, Bain RP. Impaired growth hormone secretion in the adult population. Relation to age and adiposity. J Clin Invest. 1981 May;67(5):1361-9.

90 Rudman D. Growth hormone, body composition, and aging. J Am Geriatr Soc. 1985 Nov; 33(11):800-7.

91 Sassin JF, Parker DC, Mace JW, Gotlin RW, Johnson LC, Rossman LG. Human growth hormone release: relation to slow-wave sleep and sleep-waking cycles. Science. 1969 Aug 1; 165(3892):513-5

92 Takahashi Y, Kipnis DM, Daughaday WH. Growth hormone secretion during sleep. J Clin Invest. 1968 Sep;47(9):2079-90.

93 Van Cauter E, Leproult R, Plat L. Age-related changes in slow wave sleep and REM sleep and relationship with growth hormone and cortisol levels in healthy men. JAMA. 2000 Aug 16;284(7):861-8.

94 Van Cauter E, Plat L, Scharf MB, Leproult R, Cespedes S, L'Hermite-Balériaux M, et al. Simultaneous stimulation of slow-wave sleep and growth hormone secretion by gammahydroxybutyrate in normal young men. J Clin Invest. 1997 Aug 1;100(3):745-53.
95 Besedovsky L, Ngo HVV, Dimitrov S, Gassenmaier C, Lehmann R, Born J. Auditory closed-loop stimulation of EEG slow oscillations strengthens sleep and signs of its immune-supportive function. Nat Commun. 2017;8:1984.

96 Brandenberger G, Weibel L. The 24-h growth hormone rhythm in men: sleep and circadian influences questioned. J Sleep Res. 2004 Sep;13(3):251-5.

97 Obál F, Floyd R, Kapás L, Bodosi B, Krueger JM. Effects of systemic GHRH on sleep in intact and hypophysectomized rats. Am J Physiol. 1996;270(2 Pt 1):E230-7.

98 Steiger A, Guldner J, Hemmeter U, Rothe B, Wiedemann K, Holsboer F. Effects of growth hormone-releasing hormone and somatostatin on sleep EEG and nocturnal hormone secretion in male controls. Neuroendocrinology. 1992;56(4):566-73.

99 Marshall L, Mölle M, Böschen G, Steiger A, Fehm HL, Born J. Greater efficacy of episodic than continuous growth hormone-releasing hormone (GHRH) administration in promoting slow-wave sleep (SWS). J Clin Endocrinol Metab. 1996;81(3):1009-13.

100 Obal F, Krueger JM. GHRH and sleep. Sleep Med Rev. 2004 Oct;8(5):367-77.

101 Peterfi Z, McGinty D, Sarai E, Szymusiak R. Growth hormone-releasing hormone activates sleep regulatory neurons of the rat preoptic hypothalamus. Am J Physiol Regul Integr Comp. Physiol. 2010 Jan;298(1):R14756.

102 Åström C. Interaction between sleep and growth hormone: evaluated by manual polysomnography and automatic power spectrum analysis. Acta Neurol Scand. 1995 Oct; 92(4):281-96.

103 Mendelson WB, Slater S, Gold P, Gillin JC. The effect of growth hormone administration on human sleep: a dose-response study. Biol Psychiatry. 1980 Aug;15(4):613-8.

104 Copinschi G, Nedeltcheva A, Leproult R, Morselli LL, Spiegel K, Martino E, et al. Sleep disturbances, daytime sleepiness, and quality of life in adults with growth hormone deficiency. J Clin Endocrinol Metab. 2010 May;95(5):2195-202.

105 Kerkhofs M, Van Cauter E, Van Onderbergen A, Caufriez A, Thorner MO, Copinschi G. Sleep-promoting effects of growth hormone-releasing hormone in normal men. Am J Physiol. 1993 Apr;264(4 Pt 1):E5948.

106 Perras B, Marshall L, Köhler G, Born J, Fehm HL. Sleep and endocrine changes after intranasal administration of growth hormonereleasing hormone in young and aged humans. Psychoneuroendocrinology. 1999 Oct;24(7):743-57.

107 Peker Y, Svensson J, Hedner J, Grote L, Johannsson G. Sleep apnoea and quality of life in growth hormone $(\mathrm{GH})$-deficient adults before and after 6 months of GH replacement therapy. Clin Endocrinol. $2006 \mathrm{Jul}$; 65(1):98-105.
108 Morselli LL, Nedeltcheva A, Leproult R Spiegel K, Martino E, Legros JJ, et al. Impact of GH replacement therapy on sleep in adult patients with GH deficiency of pituitary origin. Eur J Endocrinol. 2013 Apr 15;168(5): 763-70.

109 Tanriverdi F, Karaca Z, Unluhizarci K, Kelestimur F. Unusual effects of GH deficiency in adults: a review about the effects of $\mathrm{GH}$ on skin, sleep, and coagulation. Endocrine. 2014;47:679-89.

110 Bengtsson BA, Edén S, Lönn L, Kvist H, Stokland A, Lindstedt G, et al. Treatment of adults with growth hormone (GH) deficiency with recombinant human GH. J Clin Endocrinol Metab. 1993;76(2):309-17.

111 Amato G, Carella C, Fazio S, La Montagna G, Cittadini A, Sabatini D, et al. Body composition, bone metabolism, and heart structure and function in growth hormone $(\mathrm{GH})$ deficient adults before and after GH replacement therapy at low doses. J Clin Endocrinol Metab. 1993;77(6):1671-6.

112 Herbst KL, Bhasin S. Testosterone action on skeletal muscle. Curr Opin Clin Nutr Metab Care. 2004 May;7(3):271-7.

113 Andersen ML, Alvarenga TF, Mazaro-Costa $\mathrm{R}$, Hachul HC, Tufik S. The association of testosterone, sleep, and sexual function in men and women. Brain Res. 2011 Oct 6; 1416:80-104.

114 Rariy CM, et al. Higher serum free testosterone concentration in older women is associated with greater bone mineral density, lean body mass, and total fat mass: the cardiovascular health study. J Clin Endocrinol Metab. 2011 Apr;96(4):989-96.

115 Bhasin S, Storer TW, Berman N, Callegari C, Clevenger B, Phillips J, et al. The effects of supraphysiologic doses of testosterone on muscle size and strength in normal men. $\mathrm{N}$ Engl J Med. 1996;335(1):1.

116 Bhasin S, Woodhouse L, Storer TW. Proof of the effect of testosterone on skeletal muscle. J Endocrinol. 2001 Jul;170(1):27-38.

117 Boyar RM, Rosenfeld RS, Kapen J, Finkelstein JW, Roffwarg HP, Weitzman ED, et al Human puberty. Simultaneous augmented secretion of luteinizing hormone and testosterone during sleep. J Clin Invest. 1974 Sep; 54(3):609-18.

118 Luboshitzky R, Zabari Z, Shen-Orr Z, Herer P, Lavie P. Disruption of the nocturnal testosterone rhythm by sleep fragmentation in normal men. J Clin Endocrinol Metab. 2001 Mar;86(3):1134-9.

119 Luboshitzky R, Shen-Orr Z, Herer P. Seminal plasma melatonin and gonadal steroids concentrations in normal men. Arch Androl. 2002 May-Jun;48(3):225-32.

120 Borst SE, Mulligan T. Testosterone replacement therapy for older men. Clin Interv Aging. 2007 Dec;2(4):561-6.

121 Hirshkowitz M, Moore CA, O'Connor S, Bellamy M, Cunningham GR. Androgen and sleep-related erections. J Psychosom Res. 1997 Jun;42(6):541-6. 
122 Schiavi RC, White D, Mandeli J. Pituitarygonadal function during sleep in healthy aging men. Psychoneuroendocrinology. 1992 Nov;17(6):599-609.

123 Evans JI, MacLean AW, Ismail AAA, Love D. Concentrations of plasma testosterone in normal men during sleep. Nature. 1971 Jan 22;229(5282):261-2.

124 Axelsson J, Ingre M, Åkerstedt T, Holmbäck $\mathrm{U}$. Effects of acutely displaced sleep on testosterone. J Clin Endocrinol Metab. 2005 Aug;90(8):4530-5.

125 Leproult R, Van Cauter E. Effect of 1 week of sleep restriction on testosterone levels in young healthy men. JAMA. 2011 Jun 1; 305(21):2173-4.

126 Dillon EL, Durham WJ, Urban RJ, SheffieldMoore M. Hormone treatment and muscle anabolism during aging: androgens. Clin Nutr. 2010 Dec;29(6):697-700.

127 Bhasin S. Testosterone supplementation for aging-associated sarcopenia. J Gerontol A Biol Sci Med Sci. 2003 Nov;58(11):1002-8.

128 Miller KK. Androgen deficiency: effects on body composition. Pituitary. 2009;12(2): 116-24.

129 Tenover JS. Effects of testosterone supplementation in the aging male. J Clin Endocrinol Metab. 1992 Oct;75(4):1092-8.

130 Urban RJ, Bodenburg YH, Gilkison C, Foxworth J, Coggan AR, Wolfe RR, et al. Testosterone administration to elderly men increases skeletal muscle strength and protein synthesis. Am J Physiol. 1995 Nov;269(5 Pt 1):E820-6.

131 Liu PY, Swerdloff RS, Wang C. Relative testosterone deficiency in older men: clinical definition and presentation. Endocrinol Metab Clin N Am. 2005;34(4):957-72.

132 Burger HG, Dudley EC, Cui J, Dennerstein L, Hopper JL. A prospective longitudinal study of serum testosterone, dehydroepiandrosterone sulfate, and sex hormone-binding globulin levels through the menopause transition. J Clin Endocrinol Metab. 2000 Aug;85(8):2832-8.

133 Davison SL, Bell R, Donath S, Montalto JG, Davis SR. Androgen levels in adult females: changes with age, menopause, and oophorectomy. J Clin Endocrinol Metab. 2005 Jul; 90(7):3847-53.

134 Chang AY, Auchus RJ. Endocrine disturbances affecting reproduction. In: Yen \& Jaffe's reproductive endocrinology: physiology, pathophysiology, and clinical management. 8th ed. Oxford: Elsevier Inc; 2019.

135 Hannibal KE, Bishop MD. Chronic stress, cortisol dysfunction, and pain: a psychoneuroendocrine rationale for stress management in pain rehabilitation. Phys Ther. 2014 Dec;94(12):1816-25.

136 Kayali AG, Young VR, Goodman MN. Sensitivity of myofibrillar proteins to glucocorticoid-induced muscle proteolysis. Am J Physiol. 1987 May;252(5 Pt 1):E621-6.

137 Millward DJ, Garlick PJ, Nnanyelugo DO, Waterlow JC. The relative importance of muscle protein synthesis and breakdown in the regulation of muscle mass. Biochem J. 1976 Apr 15;156(1):185-8.

138 Nieman LK. Cushing's syndrome: update on signs, symptoms and biochemical screening. Eur J Endocrinol. 2015 Oct;173(4):M33-8.

139 Djaldetti M, Gafter U, Fishamn P. Ultrastructural observations in myopathy complicating Cushing's disease. Am J Med Sci. 1977;273(3):273-7.

140 Buckley TM, Schatzberg AF. Review: on the interactions of the hypothalamic-pituitaryadrenal (HPA) axis and sleep: normal HPA axis activity and circadian rhythm, exemplary sleep disorders. J Clin Endocrinol Metab. 2005 May;90(5):3106-14

141 Dickmeis T. Glucocorticoids and the circadian clock. J Endocrinol. 2009 Jan;200(1): $3-22$.

142 Weitzman ED, Zimmerman JC, Czeisler CA, Ronda J. Cortisol secretion is inhibited during sleep in normal man. J Clin Endocrinol Metab. 1983;56(2):352-8.

143 Weitzman ED, Zimmerman JC, Czeisler CA, Ronda J. Cortisol secretion is inhibited during sleep in normal man. J Clin Endocrinol Metab. 1983 Feb;56(2):352-8.

144 Treuer K, Norman TR, Armstrong SM. Overnight human plasma melatonin, Cortisol, prolactin, TSH, under conditions of normal sleep, sleep deprivation, and sleep recovery. J Pineal Res. 1996 Jan;20(1):714.

145 Weibel L, Follenius M, Spiegel K, Ehrhart J, Brandenberger G. Comparative effect of night and daytime sleep on the 24-hour cortisol secretory profile. Sleep. 1995 Sep;18(7): 549-56.

146 Castro-Diehl C, Roux AVD, Redline S, Seeman T, Shrager SE, Shea S. Association of sleep duration and quality with alterations in the hypothalamic-pituitary adrenocortical axis: the Multi-Ethnic Study of Atherosclerosis (MESA). J Clin Endocrinol Metab. 2015 Aug; 100(8):3149-58.

147 Gronfier C, Luthringer R, Follenius M, Schaltenbrand N, Macher JP, Muzet A, et al. Temporal relationships between pulsatile cortisol secretion and electroencephalographic activity during sleep in man. Electroencephalogr Clin Neurophysiol. 1997 Sep;103(3):405-8.

148 Perras B, Wagner U, Born J, Fehm HL. Improvement of sleep and pituitary-adrenal inhibition after subchronic intranasal vasopressin treatment in elderly humans. J Clin Psychopharmacol. 2003 Feb;23(1): 35-44.

149 Grimaldi D, Papalambros NA, Reid KJ, Abbott SM, Malkani RG, Gendy $M$, et al. Strengthening sleep-autonomic interaction via acoustic enhancement of slow oscillations. Sleep. 2019;42(5):zsz036.

150 Beyer I, Mets T, Bautmans I. Chronic lowgrade inflammation and age-related sarcopenia. Curr Opin Clin Nutr Metab Care. 2012;15(1):12-22.
151 Alemán H, Esparza J, Ramirez FA, Astiazaran $\mathrm{H}$, Payette $\mathrm{H}$. Longitudinal evidence on the association between interleukin- 6 and $\mathrm{C}$-reactive protein with the loss of total appendicular skeletal muscle in free-living old er men and women. Age Ageing. $2011 \mathrm{Jul}$ 40(4):469-75

152 Haren MT, Malmstrom TK, Miller DK, Patrick $\mathrm{P}$, Perry HM 3rd, Herning MM, et al. Higher C-reactive protein and soluble tumor necrosis factor receptor levels are associated with poor physical function and disability: a cross-sectional analysis of a cohort of late middle-aged african Americans. J Gerontol A Biol. 2010 Mar;65A(3):274-81.

153 Buford TW, Cooke MB, Manini TM, Leeuwenburgh C, Willoughby DS. Effects of age and sedentary lifestyle on skeletal muscle nf$\kappa b$ signaling in men. J Gerontol A Biol Sci Med Sci. 2010 May;65(5):532-7.

154 Levinger I, Howlett KF, Peake J, Garnham A, Hare DL, Jerums G, et al. Akt, AS160, metabolic risk factors and aerobic fitness in middle-aged women. Exerc Immunol Rev. 2010; 16:98-104.

155 Safdar A, Hamadeh MJ, Kaczor JJ, Raha S, deBeer J, Tarnopolsky MA. Aberrant mitochondrial homeostasis in the skeletal muscle of sedentary older adults. PLoS One. 2010 May 24;5(5):e10778.

156 Thalacker-Mercer AE, Dell'Italia LJ, Cui X, Cross JM, Bamman MM. Differential genomic responses in old vs. young humans despite similar levels of modest muscle damage after resistance loading. Physiol Genomics. 2010 Feb 4;40(3):141-9.

157 Mullington JM, Simpson NS, Meier-Ewert HK, Haack M. Sleep loss and inflammation. Best Pract Res Clin Endocrinol Metab. 2010 Oct;24(5):775-84.

158 Costamagna D, Costelli P, Sampaolesi M, Penna F. Role of inflammation in muscle homeostasis and myogenesis. Mediators Inflamm. 2015;2015:805172.

159 Reid MB, Li YP. Tumor necrosis factor- $\alpha$ and muscle wasting: a cellular perspective. Respir Res. 2001;2(5):269-72.

160 Irwin MR, Wang M, Ribeiro D, Cho HG Olmstead R, Breen EC, et al. Sleep loss activates cellular inflammatory signaling. Biol Psychiatry. 2008 Sep 15;64(6):538-40.

161 Shearer WT, Reuben JM, Mullington JM, Price NJ, Lee BN, Smith EO, et al. Soluble TNF- $\alpha$ receptor 1 and IL- 6 plasma levels in humans subjected to the sleep deprivation model of spaceflight. J Allergy Clin Immunol. 2001 Jan;107(1):165-70.

162 Meier-Ewert HK, Ridker PM, Rifai N, Regan MM, Price NJ, Dinges DF, et al. Effect of sleep loss on C-reactive protein, an inflammatory marker of cardiovascular risk. J Am Coll Cardiol. 2004 Feb 18;43(4):678-83.

163 Simpson NS, Gibbs EL, Matheson GO. Optimizing sleep to maximize performance: implications and recommendations for elite athletes. Scand J Med Sci Sports. 2017;27: 266-74. 
164 Fullagar HHK, Skorski S, Duffield R, Hammes D, Coutts AJ, Meyer T. Sleep and athletic performance: the effects of sleep loss on exercise performance, and physiological and cognitive responses to exercise. Sports Med. 2015 Feb;45(2):161-86.

165 Kant GJ, Genser SG, Thorne DR, Pfalser JL, Mougey EH. Effects of 72 hour sleep deprivation on urinary cortisol and indices of metabolism. Sleep. 1984;7(2):142-6.

166 Ng M, Fleming T, Robinson M, Thomson B, Graetz N, Margono C, et al. Global, regional, and national prevalence of overweight and obesity in children and adults during 19802013: a systematic analysis for the Global Burden of Disease Study 2013. Lancet. 2014 Aug;384(9945):766-81.

167 Chen X, Beydoun MA, Wang Y. Is sleep duration associated with childhood obesity? A systematic review and meta-analysis. Obesity. 2008 Feb;16(2):265-74.

168 Magee L, Hale L. Longitudinal associations between sleep duration and subsequent weight gain: a systematic review. Sleep Med Rev. 2012 Jun;16(3):231-41.

169 Patel SR, Hu FB. Short sleep duration and weight gain: a systematic review. Obesity. 2008 Mar; 16(3):643-53.

$170 \mathrm{Wu}$ Y, Zhai L, Zhang D. Sleep duration and obesity among adults: a meta-analysis of prospective studies. Sleep Med. 2014 Dec; 15(12):1456-62.

171 Sperry SD, Scully ID, Gramzow RH, Jorgensen RS. Sleep duration and waist circumference in adults: a meta-analysis. Sleep. 2015 Aug;38(8):1269-76.

172 Ogilvie RP, Redline S, Bertoni AG, Chen X, Ouyang P, Szklo M, et al. Actigraphy measured sleep indices and adiposity: the MultiEthnic Study of Atherosclerosis (MESA). Sleep. 2016 Sep;39(9):1701-8.

173 Locard E, Mamelle N, Billette A, Miginiac M, Munoz F, Rey S. Risk factors of obesity in a five year old population. Parental versus environmental factors. Int J Obes Relat Metab Disord. 1992 Oct;16(10):721-9.

174 Heslop P, Smith GD, Metcalfe C, Macleod J, Hart C. Sleep duration and mortality: the effect of short or long sleep duration on cardiovascular and all-cause mortality in working men and women. Sleep Med. 2002 Jul; 3(4):305-14.

175 Hasler G, Buysse DJ, Klaghofer R, Gamma A, Ajdacic V, Eich D, et al. The association between short sleep duration and obesity in young adults: a 13-year prospective study. Sleep. 2004 Jun 15;27(4):661-6.

176 Taheri S, Lin L, Austin D, Young T, Mignot E. Short sleep duration is associated with reduced leptin, elevated ghrelin, and increased body mass index. PLoS Med. 2004;1:e62.

177 Simon C, Gronfier C, Schlienger JL, Brandenberger G. Circadian and ultradian variations of leptin in normal man under continuous enteral nutrition: relationship to sleep and body temperature. J Clin Endocrinol Metab. 1998 Jun;83(6):1893-9.
178 Mullington JM, Chan JL, Van Dongen HP, Szuba MP, Samaras J, Price NJ, et al. Sleep loss reduces diurnal rhythm amplitude of leptin in healthy men. J Neuroendocrinol. 2003 Sep;15(9):851-4.

179 Shea SA, Hilton MF, Orlova C, Ayers RT, Mantzoros CS. Independent circadian and sleep/wake regulation of adipokines and glucose in humans. J Clin Endocrinol Metab. 2005;90(5):2537-44.

180 Kripke DF, Garfinkel L, Wingard DL, Klauber MR, Marler MR. Mortality associated with sleep duration and insomnia. Arch Gen Psychiatry. 2002 Feb;59(2):131-6.

181 Hirshkowitz M, Whiton K, Albert SM, Alessi C, Bruni O, DonCarlos L, et al. National sleep foundation's sleep time duration recommendations: methodology and results summary. Sleep Health. 2015 Mar;1(1):403.

182 St-Onge MP, Bormes A, Salazar I. The role of sleep duration on energy balance: an update. Curr Nutr Rep. 2016;5:278-5.

183 Knutson KL. Impact of sleep and sleep loss on glucose homeostasis and appetite regulation. Sleep Med Clin. 2007 Jun;2(2):187-97.

184 Jurado-Fasoli L, Amaro-Gahete FJ, De-La-o A, Dote-Montero M, Gutiérrez Á, Castillo MJ. Association between sleep quality and body composition in sedentary middle-aged adults. Medicine. 2018;54(5):91.

185 Kahlhöfer J, Karschin J, Breusing N, BosyWestphal A. Relationship between actigraphy-assessed sleep quality and fat mass in college students. Obesity. 2016;24(2):33541.

186 Rahe C, Czira ME, Teismann H, Berger K. Associations between poor sleep quality and different measures of obesity. Sleep Med. 2015 Oct;16(10):1225-8.

187 Ferranti R, Marventano S, Castellano S, Giogianni G, Nolfo F, Rametta S, et al. Sleep quality and duration is related with diet and obesity in young adolescent living in Sicily, Southern Italy. Sleep Sci. 2016 Apr-Jun;9(2): 117-22.

188 Rao MN, Blackwell T, Redline S, Stefanick ML, Ancoli-Israel S, Stone KL. Association between sleep architecture and measures of body composition. Sleep. 2009;32(4):48390.

189 Zimberg IZ, Crispim CA, Diniz RM, Dattilo M, Reis BG, Cavagnolli DA, et al. Gender differences in the relationship of sleep pattern and body composition in healthy adults. Sleep Sci. 2011 Feb;4(2):39-44.

190 Theorell-Haglöw J, Berne C, Janson C, Sahlin C, Lindberg E. Associations between short sleep duration and central obesity in women. Sleep. 2010;33(5):593-8.

191 Liu X, Forbes EE, Ryan ND, Rofey D, Hannon TS, Dahl RE. Rapid eye movement sleep in relation to overweight in children and adolescents. Arch Gen Psychiatry. 2008 Aug; 65(8):924-32.

192 Mai E, Buysse DJ. Insomnia: prevalence, impact, pathogenesis, differential diagnosis, and evaluation. Sleep Med Clin. 2008;3(2): 167-74.

193 Saddichha S. Diagnosis and treatment of chronic insomnia. Ann Indian Acad Neurol. 2010 Apr-Jun;13(2):94-102.

194 Janson C, Lindberg E, Gislason T, Elmasry A, Boman G. Insomnia in men: a 10-year prospective population based study. Sleep. 2001 Jun 15;24(4):425-30.

195 Foley DJ, Monjan AA, Brown SL, Simonsick EM, Wallace RB, Blazer DG. Sleep complaints among elderly persons: an epidemiologic study of three communities. Sleep. 1995 Jul;18(6):425-32.

196 Zhang Y, Jiang X, Liu J, Lang Y, Liu Y. The association between insomnia and the risk of metabolic syndrome: a systematic review and meta-analysis. J Clin Neurosci. 2021;89: $430-6$.

197 Vgontzas AN, Zoumakis M, Papanicolaou DA, Bixler EO, Prolo P, Lin HM, et al Chronic insomnia is associated with a shift of interleukin-6 and tumor necrosis factor secretion from nighttime to daytime. Metabolism. 2002 Jul;51(7):887-92.

198 Vgontzas AN, Legro RS, Bixler EO, Grayev A, Kales A, Chrousos GP. Polycystic ovary syndrome is associated with obstructive sleep apnea and daytime sleepiness: role of insulin resistance 1. J Clin Endocrinol Metab. 2001 Feb;86(2):517-20.

199 Basta M, Chrousos GP, Vela-Bueno A, Vgontzas AN. Chronic insomnia and the stress system. Sleep Med Clin. 2007 Jun;2(2): 279-91.

200 Lucassen EA, Cizza G. The hypothalamicpituitary-adrenal axis, obesity, and chronic stress exposure: sleep and the HPA axis in obesity. Curr Obes Rep. 2012 Dec;1(4):20815.

201 Motivala SJ, Tomiyama AJ, Ziegler M, Khandrika S, Irwin MR. Nocturnal levels of ghrelin and leptin and sleep in chronic insomnia. Psychoneuroendocrinology. 2009 May;34(4):540-5.

202 Timper K, Brüning JC. Hypothalamic circuits regulating appetite and energy homeostasis: pathways to obesity. Dis Model Mech. 2017 Jun 1;10(6):679-89.

203 Yildiz BO, Suchard MA, Wong ML, McCann SM, Licinio J. Alterations in the dynamics of circulating ghrelin, adiponectin and leptin in human obesity. Proc Natl Acad Sci U S A. 2004 Jul 13;101(28):10434-9.

204 Ahima RS. Revisiting leptin's role in obesity and weight loss. J Clin Invest. 2008 Jul; 118(7):2380-3.

205 Knutson KL, Galli G, Zhao X, Mattingly M, Cizza G. No association between leptin levels and sleep duration or quality in obese adults. Obesity. 2011 Dec;19(12): 2433-5.

206 Guilleminault C, Powell NB, Martinez S, Kushida C, Raffray T, Palombini L, et al. Preliminary observations on the effects of sleep time in a sleep restriction paradigm. Sleep Med. 2003 May;4(3):177-84. 
207 Spiegel K, Leproult R, L'Hermite-Balériaux M, Copinschi G, Penev PD, Van Cauter E. Leptin levels are dependent on sleep duration: Relationships with sympathovagal balance, carbohydrate regulation, cortisol, and thyrotropin. J Clin Endocrinol Metab. 2004 Nov;89(11):5762-71.

208 Porkka-Heiskanen T, Van Leeuwen WMA, Hublin C, Sallinen M, Härmä M, Hirvonen A. Prolonged sleep restriction affects glucose metabolism in healthy young men. Int J Endocrinol. 2010;2010.

209 St-Onge M-P, O’Keeffe M, Roberts AL, RoyChoudhury A, Laferrère B. Short sleep duration, glucose dysregulation and hormonal regulation of appetite in men and women. Sleep. 2012 Nov 1;35(11):1503-10.

210 Klok MD, Jakobsdottir S, Drent ML. The role of leptin and ghrelin in the regulation of food intake and body weight in humans: a review. Obes Rev. 2007 Jan;8(1):21-34.

211 Olson CA, Hamilton NA, Somers VK. Percentage of REM sleep is associated with overnight change in leptin. J Sleep Res. 2016 Aug;25(4):419-25.

212 Van Aggel-Leijssen DPC, Van Baak MA, Tenenbaum R, Campfield LA, Saris WHM. Regulation of average $24 \mathrm{~h}$ human plasma leptin level the influence of exercise and physiological changes in energy balance. Int J Obes Relat Metab Disord. 1999 Feb;23(2): 151-8.

213 Chin-Chance C, Polonsky KS, Schoeller DA. Twenty-four-hour leptin levels respond to cumulative short-term energy imbalance and predict subsequent intake. J Clin Endocrinol Metab. 2000 Aug;85(8):2685-91.

214 Van Der Lely AJ, Tschöp M, Heiman ML, Ghigo E. Biological, physiological, pathophysiological, and pharmacological aspects of ghrelin. Endocr Rev. 2004 Jun;25(3):42657.

215 Al-Disi D, Al-Daghri N, Khanam L, Al-Othman A, Al-Saif M, Sabico S, et al. Subjective sleep duration and quality influence diet composition and circulating adipocytokines and ghrelin levels in teen-age girls. Endocr J. 2010;57(10):915-23.

$216 \mathrm{Fu} \mathrm{J}$, Zhou F, Xu XQ, Zou CC, Wang CL, Huang $\mathrm{K}$, et al. Short sleep duration as a risk factor for obesity in childhood is associated with increased leptin, ghrelin, and orexin levels. Hong Kong J Paediatr. 2013;18(3): 152-8.

217 St-Onge MP. The role of sleep duration in the regulation of energy balance: effects on energy intakes and expenditure. J Clin Sleep Med. 2013 Jan 15;9(1):73-80.

218 Schmid SM, Hallschmid M, Jauch-Chara K, Born J, Schultes B. A single night of sleep deprivation increases ghrelin levels and feelings of hunger in normal-weight healthy men. J Sleep Res. 2008 Sep;17(3):331-4.

219 Spiegel K, Tasali E, Penev P, Van Cauter E. Brief communication: sleep curtailment in healthy young men is associated with decreased leptin levels, elevated ghrelin levels, and increased hunger and appetite. Ann Intern Med. 2004;141(11):846-50.

220 Benedict C, Hallschmid M, Lassen A, Mahnke C, Schultes B, Schiöth HB, et al. Acute sleep deprivation reduces energy expenditure in healthy men. Am J Clin Nutr. 2011 Jun;93(6):1229-36.

221 Schmid SM, Hallschmid M, Jauch-Chara K, Wilms B, Lehnert H, Born J, et al. Short-term sleep loss decreases physical activity under free-living conditions but does not increase food intake under time-deprived laboratory conditions in healthy men. Am J Clin Nutr. 2009 Dec;90(6):1476-82.

222 Bosy-Westphal A, Hinrichs S, Jauch-Chara K, Hitze B, Later W, Wilms B, et al. Influence of partial sleep deprivation on energy balance and insulin sensitivity in healthy women. Obes Facts. 2008;1(5):266-73.

223 Nedeltcheva AV, Kilkus JM, Imperial J, Kasza K, Schoeller DA, Penev PD. Sleep curtailment is accompanied by increased intake of calories from snacks. Am J Clin Nutr. 2009 Jan;89(1):126-33.

224 Susan MG, Daniel Castracane V, Christos S Energy homeostasis, obesity and eating disorders: recent advances in endocrinology. Obe Metab. 2004;1(1):39.

225 Fain JN, Madan AK, Hiler ML, Cheema P, Bahouth SW. Comparison of the release of adipokines by adipose tissue, adipose tissue matrix, and adipocytes from visceral and subcutaneous abdominal adipose tissues of obese humans. Endocrinology. 2004 May; 145(5):2273-82.

226 Ahima RS. Metabolic actions of adipocyte hormones: focus on adiponectin. Obesity. 2006 Feb;14(Suppl 1):9S-15S.

227 Yamauchi T, Kamon J, Waki H, Terauchi Y, Kubota N, Hara K, et al. The fat-derived hormone adiponectin reverses insulin resistance associated with both lipoatrophy and obesity. Nat Med. 2001 Aug;7(8):941-6.

228 Fallo F, Scarda A, Sonino N, Paoletta A, Boscaro M, Pagano C, et al. Effect of glucocorticoids on adiponectin: a study in healthy subjects and in Cushing's syndrome. Eur J Endocrinol. 2004;150(8):339-44.

229 Hjelmesaeth J, Flyvbjerg A, Jenssen T, Frystyk J, Ueland T, Hagen M, et al. Hypoadiponectinemia is associated with insulin resistance and glucose intolerance after renal transplantation: impact of immunosuppressive and antihypertensive drug therapy. Clin J Am Soc Nephrol. 2006 May;1(3):575-82.

230 Uchida HA, Nakamura Y, Kaihara M, Norii $\mathrm{H}$, Hanayama Y, Sugiyama H, et al. Steroid pulse therapy impaired endothelial function while increasing plasma high molecule adiponectin concentration in patients with IgA nephropathy. Nephrol Dial Transplant. 2006 Dec;21(12):3475-80.

231 Jang C, Inder WJ, Obeyesekere VR, Alford FP. Adiponectin, skeletal muscle adiponectin receptor expression and insulin resistance following dexamethasone. Clin Endocrinol. 2008 Nov;69(5):745-50.
232 Rieth N, Jollin L, Le Panse B, Lecoq AM, Arlettaz A, De Ceaurriz J, et al. Effects of shortterm corticoid ingestion on food intake and adipokines in healthy recreationally trained men. Eur J Appl Physiol. 2009 Jan;105(2): 309-13.

233 Cimmino MA, Andraghetti G, Briatore L, Salani B, Parodi M, Cutolo M, et al. Changes in adiponectin and leptin concentrations during glucocorticoid treatment: a pilot study in patients with polymyalgia rheumatica: Annals of the New York Academy of Sciences. Ann N Y Acad Sci. 2010;1193:160-3.

234 Kreiner F, Galbo H. Insulin sensitivity and related cytokines, chemokines, and adipokines in polymyalgia rheumatica. Scand J Rheumatol. 2010;39(5):402-8.

235 Lewandowski KC, Szosland K, Lewinski A. Short-term dexamethasone administration does not alter serum adiponectin or resistin concentrations in overweight and obese subjects despite an increase in insulin resistance. Clin Endocrinol. 2006 Oct;65(4):551-2.

236 Darmon P, Dadoun F, Boullu-Ciocca S, Grino $\mathrm{M}$, Alessi MC, Dutour A. Insulin resistance induced by hydrocortisone is increased in patients with abdominal obesity. Am J Physiol Endocrinol Metab. 2006 Nov; 291(5):E995-E1002.

237 Libè R, Morpurgo PS, Cappiello V, Maffini A, Bondioni S, Locatelli M, et al. Ghrelin and adiponectin in patients with Cushing's disease before and after successful transsphenoidal surgery. Clin Endocrinol. 2005 Jan; 62(1):30-6.

238 Sukumaran S, DuBois DC, Jusko WJ, Almon RR. Glucocorticoid effects on adiponectin expression. Vitam Horm. 2012;90:163-86.

239 Simpson NS, Banks S, Arroyo S, Dinges DF. Effects of sleep restriction on adiponectin levels in healthy men and women. Physiol Behav. 2010 Dec;101(5):693-8.

240 Van Cauter E, Kerkhofs M, Caufriez A, Van Onderbergen A, Thorner MO, Copinschi G. A quantitative estimation of growth hormone secretion in normal man: reproducibility and relation to sleep and time of day. J Clin Endocrinol Metab. 1992 Jun;74(6): 1441-50.

241 Honda Y, Takahashi K, Takahashi S, Azumi $\mathrm{K}$, Irie M, Sakuma M, et al. Growth hormone secretion during nocturnal sleep in normal subjects. J Clin Endocrinol Metab. 1969 Jan; 29(1):20-9.

242 Van Cauter E, Plat L. Physiology of growth hormone secretion during sleep. J Pediatr. 1996 May;128(5 Pt 2):S32-7.

243 Sassin JF, Parker DC, Johnson LC, Rossman LG, Mace JW, Gotlin RW. Effects of slow wave sleep deprivation on human growth hormone release in sleep: preliminary study. Life Sci. 1969 Dec;8(23):1299-307.

244 Bergan-Roller HE, Sheridan MA. The growth hormone signaling system: Insights into coordinating the anabolic and catabolic actions of growth hormone. General Comp Endocrinol. 2018 Mar 1;258:119-133. 
245 Rasmussen MH. Obesity, growth hormone and weight loss. Mol Cell Endocrinol. 2010 Mar;316(2):147-53.

246 Berryman DE, List EO. Growth Hormone's effect on adipose tissue: quality versus quantity. Int J Mol Sci. 2017 Jul 26;18(8):1621.

247 Vahl N, Jørgensen JOL, Skjærbæk C, Veldhuis JD, Ørskov H, Christiansen JS. Abdominal adiposity rather than age and sex predicts mass and regularity of $\mathrm{GH}$ secretion in healthy adults. Am J Physiol. Endocrinol Metab. 1997 Jun;272(6 Pt 1):E1108-16.

248 Clasey JL, Weltman A, Patrie J, Weltman JY, Pezzoli S, Bouchard C, et al. Abdominal visceral fat and fasting insulin are important predictors of 24-hour GH release independent of age, gender, and other physiological factors. J Clin Endocrinol Metab. 2001 Aug; 86(8):3845-52.

249 Iranmanesh A, Lizarralde G, Veldhuis JD. Age and relative adiposity are specific negative determinants of the frequency and amplitude of Growth Hormone (GH) secretory bursts and the half-life of endogenous GH in healthy men. J Clin Endocrinol Metab. 1991 Nov;73(5):1081-8.

250 Veldhuis JD, Iranmanesh A, Ho KKY, Waters MJ, Johnson ML, Lizarralde G. Dual defects in pulsatile growth hormone secretion and clearance subserve the hyposomatotropism of obesity in man. J Clin Endocrinol Metab. 1991 Jan;72(1):51-9.

251 Moøller N, Joørgensen JOL. Effects of growth hormone on glucose, lipid, and protein metabolism in human subjects. Endocr Rev. 2009 Apr;30(2):152-77.

252 Bengtsson B, Edén S, Lönn L, Kvist H, Stokland $A$, Lindstedt $G$, et al. Treatment of adults with growth hormone (GH) deficiency with recombinant human GH. J Clin Endocrinol Metab. 1993 Feb;76(2):309-17.

253 Takahashi S, Satozawa N. The $20-\mathrm{kD}$ human growth hormone reduces body fat by increasing lipolysis and decreasing lipoprotein lipase activity. Horm Res. 2002;58(4):15764.

254 Skaggs SR, Crist DM. Exogenous human growth hormone reduces body fat in obese women. Horm Res. 1991;35(1):19.

255 Richelsen B, Pedersen SB, Borglum JD, Moller-Pedersen T, Jorgensen J, Jorgensen JO. Growth hormone treatment of obese women for $5 \mathrm{wk}$ : effect on body composition and adipose tissue LPL activity. Am J Physiol. 1994 Feb;266(2 Pt 1):E221-61.

256 Johannsson G, Mårin P, Lönn L, Ottosson M, Stenlöf K, Björntorp P, et al. Growth hormone treatment of abdominally obese men reduces abdominal fat mass, improves glucose and lipoprotein metabolism, and reduces diastolic blood pressure 1. J Clin Endocrinol Metab. 1997 Mar;82(3):727-34

257 Franco C, Brandberg J, Lönn L, Andersson B, Bengtsson BÅ, Johannsson G. Growth hormone treatment reduces abdominal visceral fat in postmenopausal women with abdominal obesity: a 12 -month placebo-con- trolled trial. J Clin Endocrinol Metab. 2005 Mar;90(3):1466-74.

258 Bredella MA, Lin E, Brick DJ, Gerweck AV, Harrington LM, Torriani M, et al. Effects of GH in women with abdominal adiposity: a 6-month randomized, double-blind, placebo-controlled trial. Eur J Endocrinol. 2012 Apr;166(4):601-11.

259 Makimura H, Feldpausch MN, Rope AM, Hemphill LC, Torriani M, Lee H, et al. Metabolic effects of a growth hormone-releasing factor in obese subjects with reduced growth hormone secretion: a randomized controlled trial. J Clin Endocrinol Metab. 2012 Dec;97(12):4769-79.

260 Meeuwsen S, Horgan GW, Elia M. The relationship between BMI and percent body fat, measured by bioelectrical impedance, in a large adult sample is curvilinear and influenced by age and sex. Clin Nutr. 2010 Oct; 29(5):560-6.

261 Gillette-Guyonnet S, Vellas B. Body composition and age-related diseases. Mech Ageing Dev. 2003;124(3):247-8.

262 Nass R, Thorner MO. Impact of the GH-cortisol ratio on the age-dependent changes in body composition. Growth Horm IGF Res. 2002;12(3):147-61.

263 Perry HM, Morley JE, Horowitz M, Kaiser FE, Miller OK, Wittert G. Body composition and age in African-American and Caucasian women: relationship to plasma leptin levels. Metabolism. 1997 Dec;46(12):1399-405.

264 Guyenet SJ, Schwartz MW. Regulation of food intake, energy balance, and body fat mass: implications for the pathogenesis and treatment of obesity. J Clin Endocrinol Metab. 2012 Mar;97(3):745-55.

265 Münzberg H, Qualls-Creekmore E, Yu S, Morrison CD, Berthoud H-R. Hedonics act in unison with the homeostatic system to unconsciously control body weight. Front Nutr. 2016;3:6.

266 Lutter M, Nestler EJ. Homeostatic and hedonic signals interact in the regulation of food intake. J Nutr. 2009 Mar;139(3):62932.

267 Chrousos G, Vgontzas AN, Kritikou I. HPA axis and sleep; 2000.

268 Ong CW, O’Driscoll DM, Truby H, Naughton MT, Hamilton GS. The reciprocal interaction between obesity and obstructive sleep apnoea. Sleep Med Rev. 2013 Apr;17(2): 123-31.

269 Ehrmann DA. Metabolic dysfunction in PCOS: relationship to obstructive sleep apnea. Steroids. 2012 Mar 10;77(4):290-4.

270 Fernandez RC, Moore VM, Van Ryswyk EM, Varcoe TJ, Rodgers RJ, March WA, et al. Sleep disturbances in women with polycystic ovary syndrome: prevalence, pathophysiology, impact and management strategies. Nat Sci Sleep. 2018 Feb 1;10:45-64.

271 Vgontzas AN, Bixler EO, Chrousos GP, Pejovic S. Obesity and sleep disturbances: meaningful sub-typing of obesity. Arch Physiol Biochem. 2008 Oct;114(4):224-36.
272 Evans DJ, Barth JH, Burke CW. Body fat topography in women with androgen excess. Int J Obes. 1988;12(2):157-62.

273 Kahal H, Kyrou I, Uthman OA, Brown A, Johnson S, Wall PDH, et al. The prevalence of obstructive sleep apnoea in women with polycystic ovary syndrome: a systematic review and meta-analysis. Sleep Breath. 2020 Mar;24(1):339-50.

274 Tasali E, Van Cauter E, Ehrmann DA. Polycystic ovary syndrome and obstructive sleep apnea. Sleep Med Clin. 2008;3(1):37-46.

275 Swanson CM, Kohrt WM, Buxton OM, Everson CA, Wright KP, Orwoll ES, et al. The importance of the circadian system \& sleep for bone health. Metabolism. 2018;84:28-43.

276 Hirschfeld HP, Kinsella R, Duque G. Osteosarcopenia: where bone, muscle, and fat collide. Osteoporosis Int. 2017 Oct;28(10): 2781-90.

277 Naganathan V, Sambrook P. Gender differences in volumetric bone density: a study of opposite-sex twins. Osteoporos Int. $2003 \mathrm{Jul}$; 14(7):564-9.

278 Dengel D. What should i track- BMC or BMD? [Internet]. Available from: https:// dexalytics.com/news/blog-5/. Accessed 2021 Jan 1.

279 Niu J, Sahni S, Liao S, Tucker KL, DawsonHughes B, Gao X. Association between sleep duration, insomnia symptoms and bone mineral density in older boston puerto rican adults. PLoS One. 2015 Jul 6;10(7):e0132342.

280 Tian Y, Shen L, Wu J, Xu G, Yong S, Song L, et al. Sleep duration and timing in relation to osteoporosis in an elderly Chinese population: a cross-sectional analysis in the Dongfeng-Tongji cohort study. Osteoporos Int. 2015 Nov;26(11):2641-8

281 Chen G, Shen L, Wu J, Xu G, Yong S, Song $\mathrm{L}$, et al. Associations between sleep duration, daytime nap duration, and osteoporosis vary by sex, menopause, and sleep quality. J Clin Endocrinol Metab. 2014;99(8):2869-77.

282 Wang K, Wu Y, Yang Y, Chen J, Zhang D, $\mathrm{Hu} \mathrm{Y}$, et al. The associations of bedtime, nocturnal, and daytime sleep duration with bone mineral density in pre- and postmenopausal women. Endocrine. 2015 Jun; 49(2):538-48

283 Saint Martin M, Labeix P, Garet M, Thomas T, Barthélémy JC, Collet $P$, et al. Does subjective sleep affect bone mineral density in older people with minimal health disorders? The PROOF cohort. J Clin Sleep Med. 2016 Nov 15;12(11):1461-69.

284 Kim N, Choi HR, Kim SW, Kim BS, Won CW, Kim SY. Association between bone mineral density and sleep duration in the Korean elderly population. Korean J Fam Med. 2014 Mar;35(2):90-7.

285 Cunningham TD, Di Pace BS. Is self-reported sleep duration associated with osteoporosis? data from a 4-year aggregated analysis from the National Health and Nutrition Examination Survey. J Am Geriatr Soc. 2015 Jul;63(7):1401-6. 
286 Chen W, Lv H, Liu S, Liu B, Zhu Y, Chen X, et al. National incidence of traumatic fractures in China: a retrospective survey of 512187 individuals. Lancet Glob Heal. 2017 Aug;5(8):e807-e817.

287 Fu X, Zhao X, Lu H, Jiang F, Ma X, Zhu S. Association between sleep duration and bone mineral density in Chinese women. Bone. 2011 Nov;49(5):1062-6.

288 Kuriyama N, Inaba M, Ozaki E, Yoneda Y, Matsui D, Hashiguchi K, et al. Association between loss of bone mass due to short sleep and leptin-sympathetic nervous system activity. Archives of Gerontology and Geriatrics. 2017;70:201.

289 Foley D, Ancoli-Israel S, Britz P, Walsh J. Sleep disturbances and chronic disease in older adults: Results of the 2003 National Sleep Foundation Sleep in America Survey. J Psychosom Res. 2004 May;56(5):497502.

290 Specker BL, Binkley T, Vukovich M, Beare T. Volumetric bone mineral density and bone size in sleep-deprived individuals. Osteoporos Int. 2007 Jan; 18(1):93-9.

291 Lima MG, Bergamo Francisco PMS, de Azevedo Barros MB. Sleep duration pattern and chronic diseases in Brazilian adults (ISACAMP, 2008/09). Sleep Med. 2012 Feb; 13(2):139-44.

292 Casazza K, Hanks LJ, Fernandez JR. Shorter sleep may be a risk factor for impaired bone mass accrual in childhood. J Clin Densitom. 2011 Oct-Dec;14(4):453-7.

293 Moradi S, Shab-bidar S, Alizadeh S, Djafarian K. Association between sleep duration and osteoporosis risk in middle-aged and elderly women: a systematic review and metaanalysis of observational studies. Metabolism. 2017 Apr;69:199-206.

294 Marques EA, Figueiredo P, Gudnason V, Lang T, Sigurdsson G, Sigurdsson S, et al. Associations of 24-hour sleep duration and CT-derived measurements of muscle and bone: the AGES-Reykjavik study. Experimental Gerontology. 2017;93:1.

295 Zakhem E, El Hage R, Zunquin G, Jacob C, Moussa E, Theunynck D. Sleep quality is a determinant of hip bone mineral density in a group of young Lebanese men. J Med Liban. 2014;62(4):213-6.

296 Swanson CM, Shea SA, Wolfe P, Cain SW, Munch M, Vujovic N, et al. Bone turnover markers after sleep restriction and circadian disruption: a mechanism for sleep-related bone loss in humans. J Clin Endocrinol Metab. 2017 Oct 1;102(10):3722-30.

297 Swanson CM, Kohrt WM, Wolfe P, Wright KP, Shea SA, Cain SW, et al. Rapid suppression of bone formation marker in response to sleep restriction and circadian disruption in men. Osteoporos Int. 2019 Dec;30(12): 2485-93.

298 Wichers M, Schmidt E, Bidlingmaier F, Klingmüller D. Diurnal rhythm of crosslaps in human serum. Clin Chem. 1999 Oct; 45(10):1858-60.
299 Joseph F, Chan BY, Durham BH, Ahmad AM, Vinjamuri S, Gallagher JA, et al. The circadian rhythm of osteoprotegerin and its association with parathyroid hormone secretion. J Clin Endocrinol Metab. 2007 Aug; 92(8):3230-8

300 Dovio A, Generali D, Tampellini M, Berruti A, Tedoldi S, et al. Variations along the 24-hour cycle of circulating osteoprotegerin and soluble RANKL: a rhythmometric analysis. Osteoporos Int. 2008 Jan;19(1): 113-7.

301 van der Spoel E, Oei N, Cachucho R, Roelfsema F, Berbée JFP, Blauw GJ, et al. The 24hour serum profiles of bone markers in healthy older men and women. Bone. 2019 Mar;120:61-9.

302 Qvist P, Christgau S, Pedersen BJ, Schlemmer A, Christiansen C. Circadian variation in the serum concentration of C-terminal telopeptide of type I collagen (serum CTx): effects of gender, age, menopausal status, posture, daylight, serum cortisol, and fasting. Bone. 2002 Jul;31(1):57-61.

303 Lakatos P, Blumsohn A, Eastell R, Tarjan G, Shinoda H, Stern PH. Circadian rhythm of in vitro bone-resorbing activity in human serum. J Clin Endocrinol Metab. 1995 Nov; 80(11):3185-90.

304 Ledger GA, Burritt MF, Kao PC, O'Fallon WM, Riggs BL, Khosla S. Role of parathyroid hormone in mediating nocturnal and agerelated increases in bone resorption. J Clin Endocrinol Metab. 1995;80(11):3304-10.

305 Aerssens J, Declerck K, Maeyaert B, Boonen S, Dequeker J. The effect of modifying dietary calcium intake pattern on the circadian rhythm of bone resorption. Calcif Tissue Int. 1999 Jul;65(1):34-40.

306 Szulc P, Delmas PD. Biochemical markers of bone turnover: Potential use in the investigation and management of postmenopausal osteoporosis. Osteoporos Int. 2008 Dec; 19(12):1683-704.

307 Luchavova M, Zikan V, Michalska D, Raska I, Kubena AA, Stepan JJ. The effect of timing of teriparatide treatment on the circadian rhythm of bone turnover in postmenopausal osteoporosis. Eur J Endocrinol. 2011 Apr; 164(4):163-8.

308 Koivula MK, Risteli L, Risteli J. Measurement of aminoterminal propeptide of type I procollagen (PINP) in serum. Clinical Biochem. 2012 Aug;45(12):920-7.

309 Szulc P, Naylor K, Hoyle NR, Eastell R, Leary ET. Use of CTX-I and PINP as bone turnover markers: National Bone Health Alliance recommendations to standardize sample handling and patient preparation to reduce pre-analytical variability. Osteoporos Int. 2017 Sep;28(9):2541-56.

310 Tsujimoto M, Chen P, Miyauchi A, Sowa H, Krege JH. PINP as an aid for monitoring patients treated with teriparatide. Bone. 2011 Apr;48(4):798-803.

311 Fu L, Patel MS, Bradley A, Wagner EF, Karsenty G. The molecular clock mediates leptin-regulated bone formation. Cell. 2005 Sep 9;122(5):803-15.

312 Fujihara Y, Kondo H, Noguchi T, Togari A. Glucocorticoids mediate circadian timing in peripheral osteoclasts resulting in the circadian expression rhythm of osteoclast-related genes. Bone. 2014;61:1.

313 Takarada T, Xu C, Ochi H, Nakazato R, Yamada D, Nakamura S, et al. Bone resorption is regulated by circadian clock in osteoblasts. J Bone Miner Res. 2017 Apr;32(4):872-81.

314 Komoto S, Kondo H, Fukuta O, Togari A. Comparison of $\beta$-adrenergic and glucocorticoid signaling on clock gene and osteoblastrelated gene expressions in human osteoblast. Chronobiol Int. 2012 Feb;29(1):66-74.

315 Quevedo I, Zuniga AM. Low bone mineral density in rotating-shift workers. J Clin Densitom. 2010;13(4):467-9.

316 Feskanich D, Hankinson SE, Schernhammer ES. Nightshift work and fracture risk: the nurses' health study. Osteoporos Int. 2009 Apr;20(4):537-42.

317 Neumann E, Müller-Ladner U, Frommer KW. Entzündung und knochenmetabolismus. Z Rheumatol. 2014;73:342-48.

318 Neumann E, Gay S, Müller-Ladner U. The RANK/RANKL/osteoprotegerin system in rheumatoid arthritis: new insights from animal models. Arthritis and Rheumatism. 2005 Oct;52(10):2960-7.

319 Kitaura H, Kimura K, Ishida M, Kohara H, Yoshimatsu M, Takano-Yamamoto T. Immunological reaction in TNF- $\alpha$-mediated osteoclast formation and bone resorptionin vitro and in vivo. Clinical and Developmental Immunology. 2013;2013:1.

320 Geng W, Wu G, Huang F, Zhu Y, Nie J, He $\mathrm{Y}$, et al. Sleep deprivation induces abnormal bone metabolism in temporomandibular joint. Int J Clin Exp Med. 2015;8(1):395-403.

321 Vgontzas AN, Zoumakis E, Bixler EO, Lin $\mathrm{HM}$, Follett H, Kales A, et al. Adverse effects of modest sleep restriction on sleepiness, performance, and inflammatory cytokines. J Clin Endocrinol Metab. 2004 May;89(5): 2119-26.

322 Swanson CM, Shea SA, Stone KL, Cauley JA, Rosen CJ, Redline S, et al. Obstructive sleep apnea and metabolic bone disease: insights into the relationship between bone and sleep. J Bone Miner Res. Feb. 2015;30(2): 199-211.

323 Dimitri P, Rosen C. The central nervous system and bone metabolism: an evolving story. Calcif Tissue Int. May 2017;100(5):476-85.

324 Tien D, Ohara PT, Larson AA, Jasmin L. Vagal afferents are necessary for the establishment but not the maintenance of kainic acid-induced hyperalgesia in mice. Pain. 2003 Mar;102(1-2):39-49.

325 Bonnet N, Benhamou CL, Brunet-Imbault B, Arlettaz A, Horcajada MN, Richard O, et al. Severe bone alterations under $\beta 2$ agonist treatments: bone mass, microarchitecture and strength analyses in female rats. Bone. 2005 Nov;37(5):622-33. 
326 Lipski S. Effects of $\beta$ adrenergic stimulation on bone-marrow function in normal and sublethally irradiated mice: I. The effect of isoproterenol on cAMP content in bonemarrow cells in vivo. Int J Radiat Biol. 1976; 29(4):359-66.

327 Serre CM, Farlay D, Delmas PD, Chenu C. Evidence for a dense and intimate innervation of the bone tissue, including glutamatecontaining fibers. Bone. 1999 Dec;25(6): 623-9.

328 Takeda S, Elefteriou F, Levasseur R, Liu X, Zhao L, Parker KL, et al. Leptin regulates bone formation via the sympathetic nervous system. Cell. 2002 Nov 1;111(5):305-17.

329 Bonnet N, Beaupied H, Vico L, Dolleans E, Laroche N, Courteix D, et al. Combined effects of exercise and propranolol on bone tissue in ovariectomized rats. J Bone Miner Res. 2007 Apr;22(4):578-88.

330 Pierroz DD, Bouxsein ML, Rizzoli R, Ferrari SL. Combined treatment with a $\beta$-blocker and intermittent PTH improves bone mass and microarchitecture in ovariectomized mice. Bone. 2006 Aug;39(2):260-7.

331 Elefteriou F. Impact of the autonomic nervous system on the skeleton. Physiol Rev. 2018 Jul 1;98(3):1083-112.

332 Bajayo A, Bar A, Denes A, Bachar M, Kram V, Attar-Namdar M, et al. Skeletal parasympathetic innervation communicates central IL-1 signals regulating bone mass accrual. Proc Natl Acad Sci U S A. 2012 Sep 18; 109(38):15455-60.

333 Shi Y, Oury F, Yadav VK, Wess J, Liu XS, Guo XE, et al. Signaling through the M3 muscarinic receptor favors bone mass accrual by decreasing sympathetic activity. Cell Metab. 2010;122(5):231-8.

334 Mancia G. Autonomic modulation of the cardiovascular system during sleep. $\mathrm{N}$ Engl J Med. 1993 Feb 4;328(5):347-9.

335 Van de Borne P, Nguyen $H$, Biston P, Linkowski P, Degaute JP. Effects of wake and sleep stages on the 24-h autonomic control of blood pressure and heart rate in recumbent men. Am J Physiol. 1994 Feb;226(2 Pt 2): $\mathrm{H} 548-54$

336 Miglis MG. Nervous system. Oxford: Elsevier Inc.; 2017.

337 Somers VK, Dyken ME, Mark AL, Abboud FM. Sympathetic-nerve activity during sleep in normal subjects. N Engl J Med. $1993 \mathrm{Feb}$ 4;328(5):303-7.

338 Dijk DJ. Slow-wave sleep, diabetes, and the sympathetic nervous system. Proc Natl Acad Sci U S A. 2008 Jan 29;105(4):1107-8.

339 Kenney MJ, Ganta CK. Autonomic nervous system and immune system interactions. Compr Physiol. 2014 Jul;4(3):1177-1200.

340 Hansen AL, Johnsen BH, Thayer JF. Vagal influence on working memory and attention. Int J Psychophysiol. 2003 Jun;48(3): 263-74.

341 Isaksson OG, Jansson JO, Gause IA. Growth hormone stimulates longitudinal bone growth directly. Science. 1982;216:1237.
342 Wang J, Zhou J, Cheng CM, Kopchick JJ, Bondy CA. Evidence supporting dual, IGF-Iindependent and IGF-I-dependent, roles for $\mathrm{GH}$ in promoting longitudinal bone growth J Endocrinol. 2004 Feb;180(2):247-55.

343 Kupfer SR, Underwood LE, Baxter RC, Clemmons DR. Enhancement of the anabolic effects of growth hormone and insulinlike growth factor I by use of both agents simultaneously. J Clin Invest. 1993 Feb;91(2): 391-6.

344 Sims NA, Clément-Lacroix P, Da Ponte F, Bouali Y, Binart N, Moriggl R, et al. Bone homeostasis in growth hormone receptornull mice is restored by IGF-I but independent of Stat5. J Clin Invest. 2000 Nov; 106(9): 1095-103.

345 Barake M, Klibanski A, Tritos NA. Effects of recombinant human growth hormone therapy on bone mineral density in adults with growth hormone deficiency: a meta-analysis. J Clin Endocrinol Metab. 2014 Mar; 99(3):852-60.

346 Xue P, Wang Y, Yang J, Li Y. Effects of growth hormone replacement therapy on bone mineral density in growth hormone deficient adults: a meta-analysis. Int J Endocrinol. 2013;2013:1.

347 Landin-Wilhelmsen K, Nilsson A, Bosaeus I, Bengtsson BÅ. Growth hormone increases bone mineral content in postmenopausal osteoporosis: a randomized placebo-controlled trial. J Bone Miner Res. 2003 Mar; 18(3):393-405.

348 Gillberg P, Mallmin H, Petrén-Mallmin M, Ljunghall S, Nilsson AG. Two years of treatment with recombinant human growth hormone increases bone mineral density in men with idiopathic osteoporosis. J Clin Endocrinol Metab. 2002 Nov;87(11):4900-6.

349 Grinspoon SK, Baum HBA, Peterson S, Klibanski A. Effects of rhIGF-I administration on bone turnover during short-term fasting. J Clin Invest. 1995 Aug;96(2):900-6.

350 Ghiron LJ, Thompson JL, Holloway L, Hintz RL, Butterfield GE, Hoffman AR, et al. Effects of recombinant insulin-like growth factor-I and growth hormone on bone turnover in elderly women. J Bone Miner Res. 1995 Dec;10(12):1844-52.

351 Grinspoon S, Baum H, Lee K, Anderson E, Herzog D, Klibanski A. Effects of short-term recombinant human insulin-like growth factor I administration on bone turnover in osteopenic women with anorexia nervosa. J Clin Endocrinol Metab. 1996 Nov;81(11): 3864-70.

352 Grinspoon S, Thomas L, Miller K, Herzog D, Klibanski A. Effects of recombinant human IGF-I and oral contraceptive administration on bone density in anorexia nervosa. J Clin Endocrinol Metab. 2002 Jun;87(6):2883-91.

353 Misra M, McGrane J, Miller KK, Goldstein MA, Ebrahimi S, Weigel T, et al. Effects of rhIGF-1 administration on surrogate markers of bone turnover in adolescents with anorexia nervosa. Bone. 2009 Sep;45(3):493-8.
354 Boonen S, Rosen C, Bouillon R, Sommer A McKay M, Rosen D, et al. Musculoskeletal effects of the recombinant human IGF-I/ IGF binding protein-3 complex in osteoporotic patients with proximal femoral fracture: a double-blind, placebo-controlled pilot study. J Clin Endocrinol Metab. 2002 Apr;87(4):1593-9.

355 Weissberger AJ, Anastasiadis AD, Sturgess I, Martin FC, Smith MA, Sönksen PH. Recombinant human growth hormone treatment in elderly patients undergoing elective total hip replacement. Clin Endocrinol. 2003 Jan; 58(1):99-107.

356 Hedström M, Sääf M, Brosjö E, Hurtig C, Sjöberg K, Wesslau A, et al. Positive effects of short-term growth hormone treatment on lean body mass and BMC after a hip fracture: a double-blind placebo-controlled pilot study in 20 patients. Acta Orthop Scand. 2004;75(4):394-401.

357 Ducy P, Amling M, Takeda S, Priemel M, Schilling AF, Beil FT, et al. Leptin inhibits bone formation through a hypothalamic relay: a central control of bone mass. Cell. 2000 Jan 21;100(2):197-297.

358 Cornish J, Callon KE, Bava U, Lin C, Naot D, Hill BL, et al. Leptin directly regulates bone cell function in vitro and reduces bone fragility in vivo. J Endocrinol. 2002 Nov; 175(2): 405-15.

359 Gordeladze JO, Drevon CA, Syversen U, Reseland JE. Leptin stimulates human osteoblastic cell proliferation, de novo collagen synthesis, and mineralization: impact on differentiation markers, apoptosis, and osteoclastic signaling. J Cell Biochem. 2002; 85(4):825-36.

360 Holloway WR, Collier FM, Aitken CJ, Myers DE, Hodge JM, Malakellis M, et al. Leptin inhibits osteoclast generation. J Bone Miner Res. 2002;17(2):200.

361 Thomas T, Gori F, Khosla S, Jensen MD, Burguera B, Riggs BL. Leptin acts on human marrow stromal cells to enhance differentiation to osteoblasts and to inhibit differentiation to adipocytes. Endocrinology. 1999 Apr;140(4):1630-8.

362 McCarthy A, Wafford K, Shanks E, Ligocki M, Edgar DM, Dijk DJ. REM sleep homeostasis in the absence of REM sleep: effects of antidepressants. Neuropharmacology. 2016 Sep;108:415-25.

363 Little JP, Phillips SM. Resistance exercise and nutrition to counteract muscle wasting. Applied Physiol Nutr Metab. 2009 Oct; 34(5):817-28.

364 Garber CE, Blissmer B, Deschenes MR, Franklin BA, Lamonte MJ, Lee IM, et al Quantity and quality of exercise for developing and maintaining cardiorespiratory, musculoskeletal, and neuromotor fitness in apparently healthy adults: guidance for prescribing exercise. Med Sci Sports Exerc. 2011 Jul;43(7):1334-59. 
365 Biolo G, Maggi SP, Williams BD, Tipton KD, Wolfe RR. Increased rates of muscle protein turnover and amino acid transport after resistance exercise in humans. Am J Physiol. 1995 Mar;268(3 Pt 1):E514-20.

366 Phillips SM, Tipton KD, Aarsland A, Wolf SE, Wolfe RR. Mixed muscle protein synthesis and breakdown after resistance exercise in humans. Am J Physiol. 1997 Jul;85(1 Pt 1): E99-107.

367 Burd NA, West DW, Moore DR, Atherton PJ, Staples AW, Prior T, et al. Enhanced amino acid sensitivity of myofibrillar protein synthesis persists for up to $24 \mathrm{~h}$ after resistance exercise in young men. J Nutr. 2011 Apr 1;141(4):568-73.

368 Joanisse S, Lim C, McKendry J, Mcleod JC, Stokes T, Phillips SM. Recent advances in understanding resistance exercise traininginduced skeletal muscle hypertrophy in humans. F1000Res. 2020 Feb 24;9:F1000 Faculty Rev-141.

369 Saner NJ, Lee MJ, Pitchford NW, Kuang J, Roach GD, Garnham A, et al. The effect of sleep restriction, with or without high-intensity interval exercise, on myofibrillar protein synthesis in healthy young men. J Physiol. 2020 Apr;598(8):1523-36.

370 Monico-Neto M, Antunes HK, Lee KS, Phillips SM, Giampá SQ, Souza Hde S, et al. Resistance training minimizes catabolic effects induced by sleep deprivation in rats. Appl Physiol Nutr Metab. 2015 Nov;40(11):114350.

371 Trommelen J, Kouw IWK, Holwerda AM, Snijders T, Halson SL, Rollo I, et al. Presleep dietary protein-derived amino acids are incorporated in myofibrillar protein during postexercise overnight recovery. Am J Physiol Endocrinol Metab. 2018 May 1; 314(5):E457-67.

372 Groen BBL, Res PT, Pennings B, Hertle E, Senden JM, Saris WH, et al. Intragastric protein administration stimulates overnight muscle protein synthesis in elderly men. Am J Physiol Endocrinol Metab. 2012 Jan 1; 302(1):E52-60.

373 Kouw IWK, Holwerda AM, Trommelen J, Kramer IF, Bastiaanse J, Halson SL, et al. Protein ingestion before sleep increases overnight muscle protein synthesis rates in healthy older men: a randomized controlled trial. J Nutr. 2017 Dec;147(12):2252-61.

374 Res PT, Groen B, Pennings B, Beelen M, Wallis GA, Gijsen AP, et al. Protein ingestion before sleep improves postexercise overnight recovery. Med Sci Sports Exerc. 2012 Aug;44(8):1560-9.

375 Knuiman P, Van Loon LJC, Wouters J, Hopman M, Mensink M. Protein supplementation elicits greater gains in maximal oxygen uptake capacity and stimulates lean mass accretion during prolonged endurance training: a double-blind randomized controlled trial. Am J Clin Nutr. 2019 Aug 1;110(2): 508-18.

376 Snijders T, Res PT, Smeets JS, van Vliet S, van Kranenburg J, Maase K, et al. Protein ingestion before sleep increases muscle mass and strength gains during prolonged resistance-type exercise training in healthy young men. J Nutr. 2015 Jun;145(6):117884.

377 Nielsen LS, Danielsen KV, Sørensen TIA. Short sleep duration as a possible cause of obesity: critical analysis of the epidemiological evidence. Obesity Rev. 2011 Feb;12(2): 78-92.

378 Thomson CA, Morrow KL, Flatt SW, Wertheim BC, Perfect MM, Ravia JJ, et al. Relationship between sleep quality and quantity and weight loss in women participating in a weight-loss intervention trial. Obesity. 2012 Jul;20(7):1419-25.

379 Wakaba K, Sasai H, Nakata Y. Associations of objectively measured physical activity and sleep with weight loss maintenance: a preliminary study of Japanese adults. Behav Sci. 2020 Jan;10(1):3.

380 Wang X, Sparks JR, Bowyer KP, Youngstedt $\mathrm{SD}$. Influence of sleep restriction on weight loss outcomes associated with caloric restriction. Sleep. 2018;41(5).

381 Chaput JP, Tremblay A. Sleeping habits predict the magnitude of fat loss in adults exposed to moderate caloric restriction. Obes Facts. 2012;5(4):561-6.

382 Verhoef SPM, Camps SGJA, Gonnissen HKJ, Westerterp KR, Westerterp-Plantenga MS. Concomitant changes in sleep duration and body weight and body composition during weight loss and 3-mo weight mainte- nance. Am J Clin Nutr. 2013 Jul;98(1):2531.

383 Claes L, Recknagel S, Ignatius A. Fracture healing under healthy and inflammatory conditions. Nat Rev Rheumatol. 2012 Jan 31; 8(3):133-43.

384 Fazzalari NL. Bone fracture and bone fracture repair. Osteoporos Int. 2011 Jun;22(6): 2003-6.

385 Cadet ER, Yin B, Schulz B, Ahmad CS, Rosenwasser MP. Proximal humerus and humeral shaft nonunions. J Am Acad Orthop Surg. 2013 Sep;21(9):538-47.

386 Gaston MS, Simpson AHRW. Inhibition of fracture healing. J Bone Joint Surg Br. 2007 Dec;89(12):1553-60.

387 Xu X, Wang L, Chen L, Su T, Zhang Y, Wang $\mathrm{T}$, et al. Effects of chronic sleep deprivation on bone mass and bone metabolism in rats. J Orthop Surg Res. 2016;11:87.

388 Xu X, Wang R, Sun Z, Wu R, Yan W, Jiang $\mathrm{Q}$, et al. Trehalose enhances bone fracture healing in a rat sleep deprivation model. Ann Transl Med. 2019 Jul;7(14):297.

389 Gertz ER, Silverma NE, Wise KS, Hanson KB, Alekel DL, Stewart JW, et al. Contribution of serum inflammatory markers to changes in bone mineral content and density in postmenopausal women: a 1-year investigation. J Clin Densitom. 2010;13(3): $277-82$.

390 Ngo HV, Martinetz T, Born J, Mölle M. Auditory closed-loop stimulation of the sleep slow oscillation enhances memory. Neuron. 2013;78(3):545-53.

391 Ferster ML, Lustenberger C, Karlen W. Configurable mobile system for autonomous high-quality sleep monitoring and closedloop acoustic stimulation. IEEE Sens Lett. 2019;3(5):1.

392 Santiago JCP, Ngo H-V, Jickeli C, Peter A, Hallschmid M. Intensifying sleep slow oscillations does not improve metabolic control in healthy men. Psychoneuroendocrinology. 2019;99:1.

393 Möller-Levet CS, Archer SN, Bucca G, Laing EE, Slak A, Kabiljo R, et al. Effects of insufficient sleep on circadian rhythmicity and expression amplitude of the human blood transcriptome. Proc Natl Acad Sci U S A. 2013 Mar 19;110(12):E1132-41. 